\title{
Wh-P and the Intervention Effect of negation
}

\author{
Aiqing Wang \\ Lancaster University, UK \\ aiqing.wang@lancaster.ac.uk
}

DOI: http://doi.org/ 10.36892/ijlls.v3i1.477

\begin{tabular}{|c|c|}
\hline $\begin{array}{l}\text { Received: } \\
\text { 04/11/2020 }\end{array}$ & $\begin{array}{l}\text { Abstract } \\
\text { Following the Government and Binding theory mainly developed by Chomsky }\end{array}$ \\
\hline $\begin{array}{l}\text { Accepted: } \\
\text { 06/03/2021 }\end{array}$ & $\begin{array}{l}\text { (1981, 1982, 1986), I explore wh-P and the Intervention Effect of negation in } \\
\text { Late Archaic Chinese (LAC). I propose that the inverted order of wh-P in LAC } \\
\text { is generated via PP inversion followed by the separate preposing of wh and P. } \\
\text { The wh-complement raises to [Spec, PP] and further moves to the specifier }\end{array}$ \\
\hline $\begin{array}{l}\text { Keywords: } \\
\text { Syntax, Late Archaic } \\
\text { Chinese, wh-P, } \\
\text { Intervention Effect, } \\
\text { negation. }\end{array}$ & $\begin{array}{l}\text { position of a functional projection. If the wh-PP is base-generated } \\
\text { preverbally, the preposition moves to the head position of the functional } \\
\text { projection directly; if the wh-PP is base-generated postverbally, the } \\
\text { preposition must first incorporate to a VO and then move to the head position } \\
\text { of the functional projection through excorporation. In terms of the } \\
\text { Intervention Effect, wh-arguments and adverbials that usually move to the } \\
\text { Low focus position below negation are subject to a blocking effect caused by } \\
\text { negation, so these wh-phrases have to land in the High focus position above } \\
\text { negation which is expected to accommodate 'high' adverbials exclusively. I } \\
\text { argue that the Intervention Effect in LAC is a consequence of Q-binding as } \\
\text { feature movement of [wh], interacting with fronting into the hierarchy of } \\
\text { clause-internal positions driven by [Focus] feature. }\end{array}$ \\
\hline
\end{tabular}

\section{INTRODUCTION}

Archaic Chinese refers to the language of the early and middle Zhou (11thc BC-221 BC) period (Karlgren 1923, Djamouri et al 2012). I follow Wang (1958), Zhou (1963) and Peyraube (2002) in terming Archaic Chinese during the Warring States period (475-221 BC) as Late Archaic Chinese (LAC). This historical period contains well-established classics, including historical texts such as Zuozhuan and Guoyu and philosophical texts such as Analects and Zhuangzi, and grammatical and lexical constructions of the writing during this era are fundamentally consistent. More significantly, LAC exhibits robust characteristics disparate from not only modern Mandarin, but also the Chinese language during the following Han Dynasty (2ndc BC-2ndc AD), which was regarded as a crucial transitional period with multiple typological changes (Xu 2006, Aldridge 2015). Afterwards, the authentic spoken language began to diverge from the written one due to natural linguistic change, so I exclude texts from the Han Dynasty onwards. In terms of Chinese prior to 5thc $\mathrm{BC}$, it is incompletely known in a form of divinatory formulae carved on oracle bones (Shaughnessy 1985, Norman 1988: 4, 83, Pulleyblank 1995: 3-4, Wilkinson 2000: 22, Peyraube and $\mathrm{Wu}$ 2005, Peyraube 2008, Dong 2014: 80-81). Therefore, in this paper, I focus on LAC only.

Texts in LAC predominantly display an SVO word order, with objects appearing in a postverbal position. However, there are contexts in which nominal and pronominal objects appear preverbally in the low TP-internal domain (Aldridge 2010). According to $\mathrm{Xu}$ and $\mathrm{Li}$ (1993), wh and non-wh object preposing in LAC is correlated to focus. Such clause-internal 
movement is driven by obligatory preverbal positioning of non-subject wh-elements of LAC which is a wh-fronting language. LAC requires VP-internal wh-phrases to raise from their base position to a preverbal position in the 'low IP area' (dubbed by Paul (2005)) between TP and vP (Aldridge 2010). Example (1) illustrates that a simplex wh moves to a preverbal position in the medial domain when acting as a direct object.

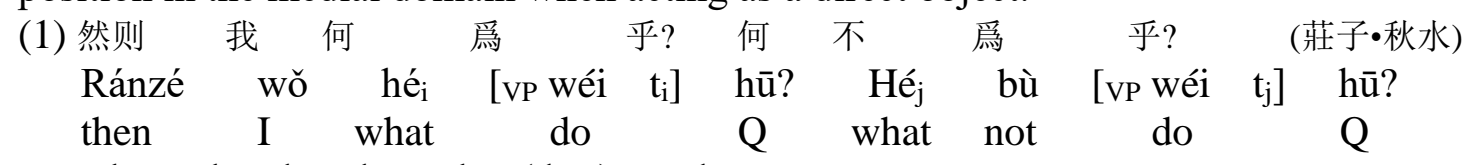

'Then what do I do? What (do I) not do?'

In LAC, there are altogether four landing sites for $w h$-fronting: the External topic position is in the left periphery (CP domain), and other landing sites are in the 'low IP area' (IP domain). The Internal topic position precedes the High focus position, and both of them intervene between subject and negation; the Low focus position is below negation and above $v \mathrm{P}$. Clausal positions for both $w h$ - and non-wh-fronting are stated in (2), including four landing sites, $w h$ base positions, medial elements and a key diagnostic element 獨 $d \dot{u}$ which always immediately precedes negation. The relevant orders among all positions, medial elements and the key diagnostic element have been verified empirically (Wang 2013, 2015, 2016).

(2) Clausal positions for $w h$ - and non-wh-fronting:

External topic position $>$ Subject $>$ Internal topic position $>$ High focus position $>$ High $w h$ base position $>$ Modal adverbs $>$ Aspectual/temporal adverbs $>$ 獨 $d \dot{u}>$ Negation $>$ Low focus position $>$ Low $w h$ base position $>$ Root modal verbs $>v \mathrm{P}$

2015, 2016)

(Adapted from Wang 2013,

One purpose of this article is to account for the derivation of the inverted wh-preposition (wh-P) order and propose a unified analysis of both moved wh- and non-wh-PPs. The other research purpose is to reveal the Intervention Effect of negation on VP-internal $w h$-DPs and wh-complements of adverbials. This article contains empirical data for the development of syntactic theory and sheds light on the comprehension of LAC as an extant language distinct from its modern counterpart.

In this article, I first investigate the derivation of $w h-\mathrm{P}$ and propose a theory of PP inversion followed by separate movement of $w h$ and P. I then discuss the Intervention Effect and argue that $w h$-arguments and $w h$-adverbials that are supposed to move to some focus position are subject to the Intervention Effect triggered by negation. I suggest that the Intervention Effect in LAC is a result of Q-binding as feature movement of [wh], along with the hierarchy of clausal positions.

\section{Wh-P}

In this section, I explore the construction $w h$-P. There are altogether five potential explanations for the inverse order of $w h$-P: 1) inversion within PP, 2) mere $w h$-fronting, with the preposition stranded in its base position, 3) inversion within PP, with the preposition is then pied-piped with the $w h$ to the landing site, 4) inversion within PP, followed by PP movement, and 5) inversion within PP, followed by separate movement of $w h$ and P.

The first approach is inversion within PP. Although this approach applies well to certain non-wh-PPs, it fails to account for DP-Adv-P-VP derived from Adv-P-DP-VP. Moreover, this approach does not apply to $w h$-PPs, because it predicts wrong orders for $w h$-PPs base- 
generated postverbally: *V(-O)-wh-P for arguments and *VP-wh-P for adjuncts, yet the attested surface orders are $w h-\mathrm{P}-\mathrm{V}(-\mathrm{O})$ and $w h-\mathrm{P}-\mathrm{VP}$ respectively. So $w h-\mathrm{P}$ in LAC cannot be induced by mere inversion within PP.

The second potential approach only involves $w h$-fronting, with the preposition stranded in situ. Since this approach indicates that there could be intervening elements between the fronted $w h$ and stranded P, five types of $w h$-PPs cannot be accounted for by this approach: 1) preverbal non-reason adjuncts with a surface order wh-P-VP, 2) preverbal arguments with a surface order $w h-\mathrm{P}-\mathrm{V}(-\mathrm{O}), 3)$ preverbal non-reason adjuncts with a surface order VP-wh-P derived from VP-fronting, 4) preverbal reason adjuncts with a surface order $w h-\mathrm{P}-\mathrm{VP}$, and 5) postverbal arguments with a surface order $w h-\mathrm{P}-\mathrm{V}(-\mathrm{O})$. The strategy of mere $w h$-fronting yet $\mathrm{P}$-stranding predicts infelicitous structures for each type of wh-PPs: 1) *wh-X-P-VP where $\mathrm{X}=\mathrm{Neg} / \mathrm{Adv} / \mathrm{FM}$ (fronting marker), 2) $* w h-\mathrm{X}-\mathrm{P}-\mathrm{V}(-\mathrm{O})$ where $\mathrm{X}=\mathrm{Neg} / \mathrm{Adv} / \mathrm{FM}, 3) * w h$-VP-P, 4) $* w h-\mathrm{FM}-\mathrm{P}-\mathrm{VP}$, and 5)*wh-V(-O)-P. As a consequence, this approach is ruled out.

The third potential approach is comprised of two parts: wh-DP first fronts to [Spec, PP], and then it further moves to the specifier of a functional projection, pied-piping the preposition with it. Such a combination of PP inversion and pied-piping satisfies the Head Movement Constraint (HMC) and Condition on Extraction Domain (CED) (Huang 1982, Travis 1984, Roberts 2001) and explains the motivation for P-movement; besides, it accounts for the unfeasibility of $* \mathrm{VP}-w h-\mathrm{P}$ and lack of intervening element between $w h$ and $\mathrm{P}$. However, this approach fails to account for the complementary distribution of FMs and prepositions (see below for detailed discussion), so it does not hold.

The fourth potential approach is PP inversion followed by PP movement: $w h$-DP first fronts to [Spec, PP], and then the whole PP moves to the specifier of a functional projection. This approach shares similar strengths with the approach combining PP inversion and pied-piping. Nonetheless, the movement of the whole PP fails to enable wh to occupy a clausal specifier position, and hence it fails to satisfy the licensing requirement of $w h$. Furthermore, the assumption of PP inversion followed by PP movement makes three wrong predictions: it predicts *P-DP-VP (derived from VP-P-DP) for non-wh-PPs and *DP-P-FM-VP (derived from P-DP-VP or VP-P-DP) for both $w h$ - and non-wh-PPs, but neither order is attested. Moreover, it does not expect DP-Adv-P-VP (derived from P-DP-VP or VP-P-DP) for non$w h$-PPs, yet this order is indeed feasible. Therefore, this approach is invalid.

Since data in LAC suggests that the first four potential theories fail to account for the wh-P structure (see (Wang 2016) for detailed discussions), I adopt the fifth theory. This approach involves two steps. First, the wh-complement raises to the specifier position of a PP, generating a $w h$-P order. Second, the $w h$-element raises to the specifier of a functional projection, and the preposition is fronted to the head of the functional projection accordingly.

Take sentence (3a) as an example. Its tree structure in (3b) illustrates the first step, i.e. inversion within PP, while (3c) shows the second step, namely the separate raising of the whcomplement 惡 $w \bar{u}$ and the preposition 乎 $h \bar{u}$. The canonical order of the first question in (3a) is V-P-wh, as indicated by the order V-P-DP in the second question that is parallel to the first one. The verb 比 $b \check{c}$ 'to compare' can take a theme DP argument followed by a goal argument packed in a $\mathrm{PP}$, and the pattern is $\mathrm{V}-\mathrm{DP}_{1}-\mathrm{P}-\mathrm{DP}_{2}$. In example (3a), the latter, rhetorical question involving a non-wh-DP and PP indicates the canonical order, i.e. $b \check{c}$-DP $\mathrm{DP}_{1}-\mathrm{P}-\mathrm{DP}_{2}$. In the former, interrogative question, the goal argument is a wh-PP which is subject to obligatory $w h$-fronting, so the $w h$-complement raises out of its base position following the DP to a position preceding the verb, and the preposition $h \bar{u}$ 'to' also fronts to a preverbal position.

\begin{tabular}{|c|c|c|c|c|c|c|}
\hline & 將 & & & 予 & 哉? & $($ 莊子•內篇・人間世) \\
\hline $\begin{array}{l}\text { Rǔ } \\
\text { yo }\end{array}$ & $\begin{array}{r}\text { jiāng } \\
\text { Fut }\end{array}$ & $\begin{array}{l}w \bar{u}_{i} \\
\text { what }\end{array}$ & $\begin{array}{l}h \bar{u}_{j} \\
\text { to }\end{array}$ & $\begin{array}{l}\text { [vp bǐ } \\
\text { compare }\end{array}$ & $\begin{array}{l}\text { yú } \\
\text { me }\end{array}$ & $\begin{array}{c}\text { zāi? } \\
\text { Q }\end{array}$ \\
\hline
\end{tabular}


若將比予 于 文 木 邪? Ruò jiāng [vp bǐ yú [pp yú [wén mù]] yé ? you Fut compare me to useful wood Q

'To what will you compare me? Will you compare me to useful wood?' b. $\mathrm{TP}$

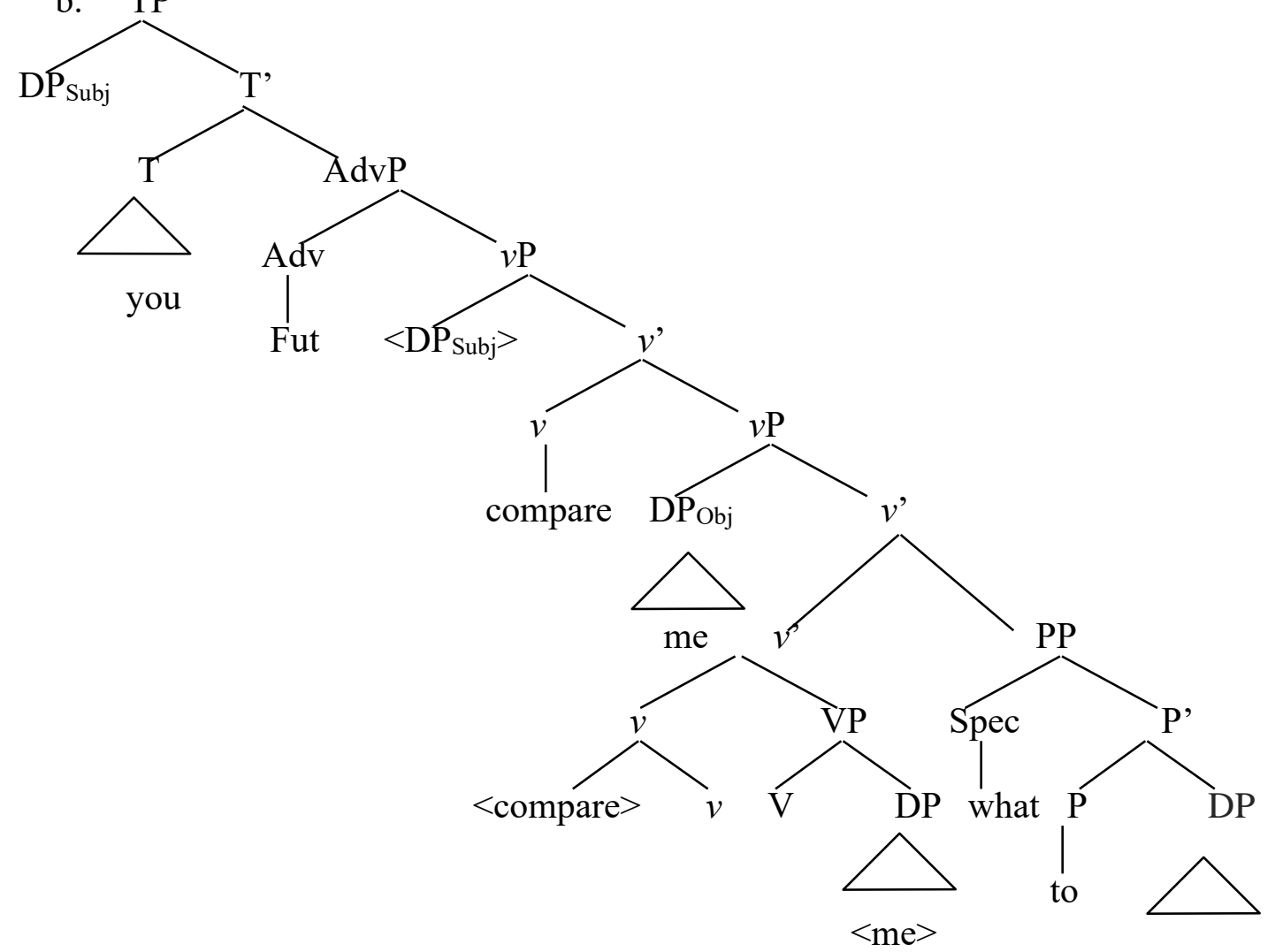

$<$ what $>$

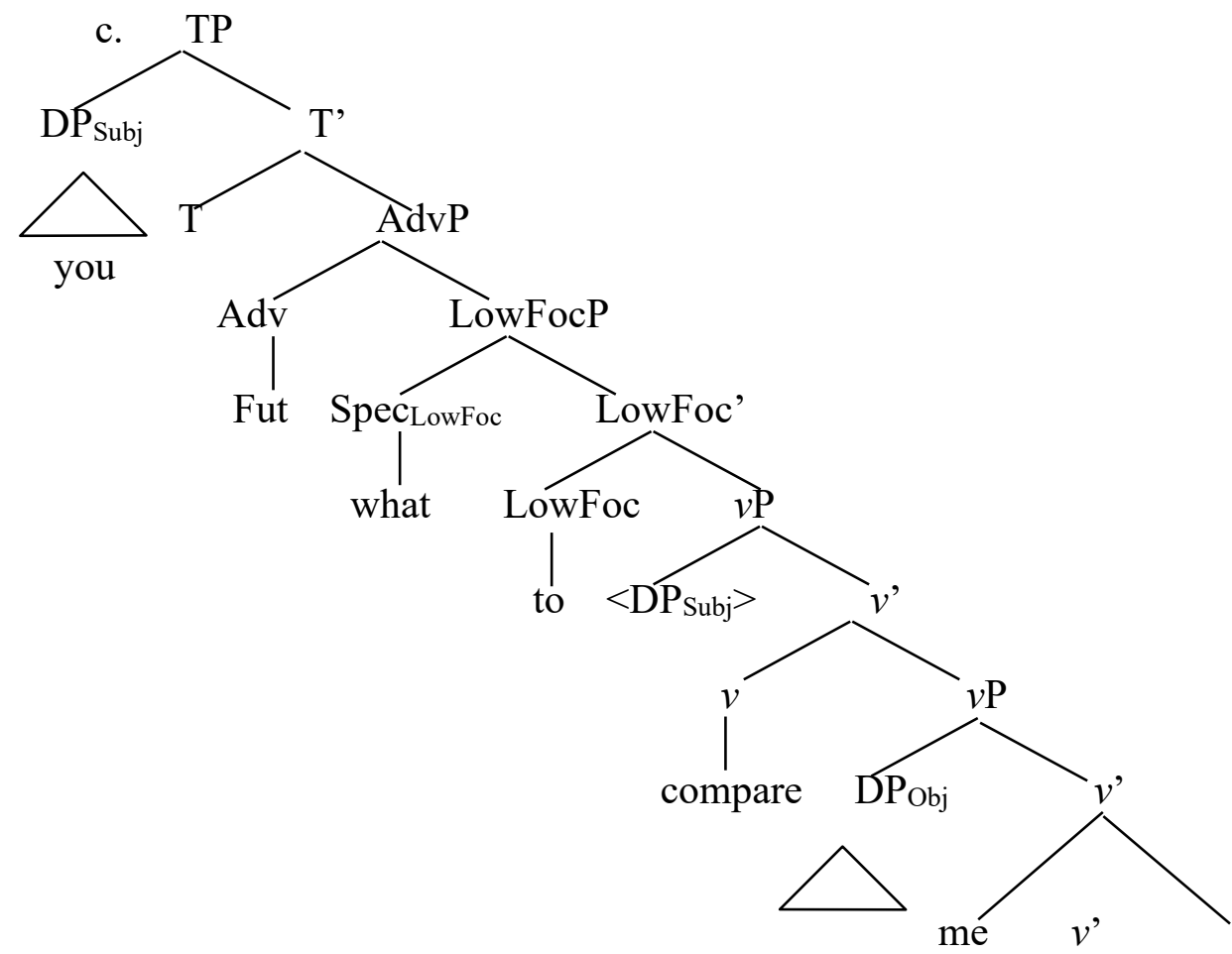




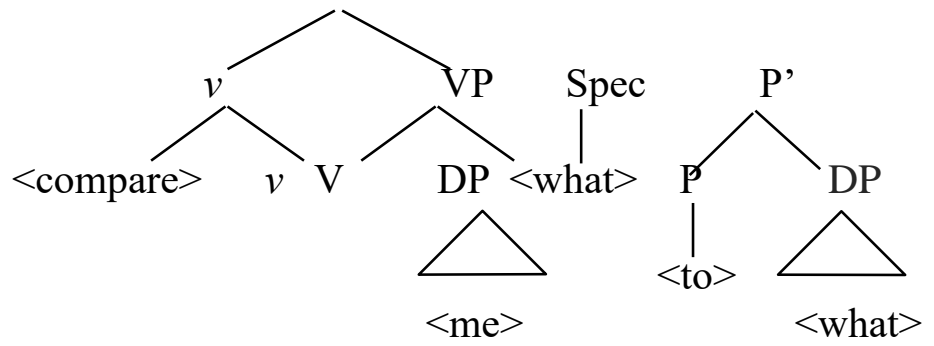

In (3a), the former question and the latter rhetorical question form a pair, and the latter contains a non-wh-PP argument base-generated postverbally. Since the wh- and non-whconstructions in these two questions are parallel, it is reasonable to analyse the $w h$-phrase 惡 乎 $w \bar{u} h \bar{u}$ in the former question as a PP as well. To further support the statement of 惡乎 $w \bar{u} h \bar{u}$ as a PP, I show that the bare $w h$-word 惡 $w \bar{u}$ can be employed as a nominal in other interrogative constructions (4a-b), and 乎 $h \bar{u}$ can alternatively act as a preposition 'than', 'in' or 'from' $(4 \mathrm{c} / \mathrm{d} / \mathrm{e})$. There is no denying the fact that $h \bar{u}$ might function as an exclamative particle, but in that situation, $h \bar{u}$ appears in a sentence-final position. So, in (3a), it should be a preposition.

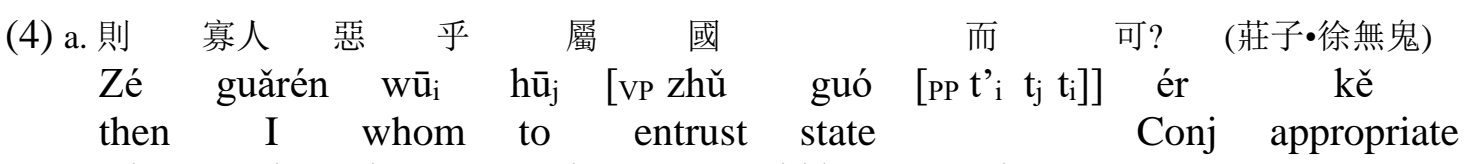

'Then to whom do I entrust the state would be appropriate?'

b. 吾 將 惡 許 用 之? 非樂上)

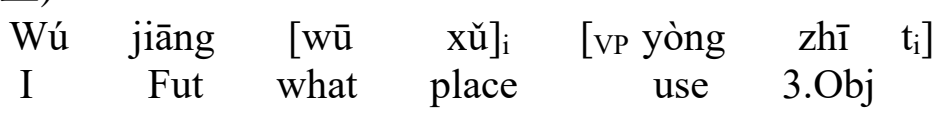

'In what place will I use them?'

c. 福 輕 乎 羽, 莫之 知 載;

Fú qīng hū yǔ, mò zhī zhī zài;

luck light than feather not it know carry

禍重 乎地, 莫之知 避 (莊子・人間世; Feng

1996: 330)

huò zhòng hū dì, mò zhī zhī bì

misfortune heavy than earth none it know avoid though

'Even though good fortune is lighter than a feather, they don't know how to take it; even disaster is heavier than the earth; they don't know how to avoid it'

d. 榮辱之責 在乎已, 而不在乎人(韓非 子•大體)

Róngrǔ zhī zé zài hū jĭ, ér bú zài hū rén honour.shame Gen responsibility be.in in self Conj not be.in in others 'The responsibility of honor and shame is on oneself, not on others'

e. 異乎吾所聞

(論 語•子張)

Yì hū wú suǒ wén

different from I SUO hear

'(This is) different from what I heard'

I state that a fronted element does not occupy the edge of $v \mathrm{P}$ (Aldridge 2010), but a 
specifier node of some functional projection, following Paul's $(2002,2005)$ analysis on positions between TP and $v \mathrm{P}$ in modern Mandarin.

First, supposing the presumption of object preposing targeting the edge of $v \mathrm{P}$ was adopted, it would imply a single position for fronted elements, contrary to examples in (5) involving more than one raised element. Moreover, it would be hard to account for examples in (6) in which DPs have been fronted into the left periphery, because the edge of $v \mathrm{P}$ is lower than TP and hence cannot accommodate preposed DPs in the CP area.

(5) a. 是以 不 我 知

道德經)

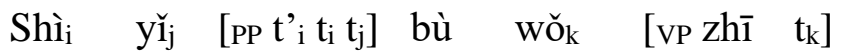

this for not me understand

'(People) for this do not understand me'

b. 然則 何以惡 乎 紿也? (穀梁傳・ 僖公元年)

Ránzé hé $e_{i} \quad \check{y}_{j} \quad\left[{ }_{P P} t^{\prime}{ }_{i} t_{i} t_{j}\right] \quad w \bar{u}_{k} \quad h \bar{u}_{1} \quad\left[P P t^{\prime}{ }_{k} t_{1} t_{k}\right] \quad[v p$ dài] yě?

then what for what with delude Decl

'Then what for and what with to delude?'

(6) a. 御

子晉解)

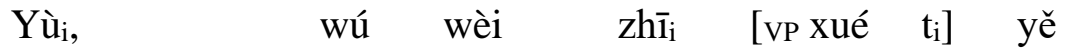

driving.chariot I not.yet 3.Obj learn Decl

'Driving a chariot, I have not learned it'

b. 其 緌 也, 吾 未 之

(家 語・冠頌)

[Qí ruí] $]_{i}$ yě, wú wèi zh̄̄i [vp wén $\mathrm{t}_{\mathrm{i}}$ ]

Gen banner Decl I not.yet 3.Obj hear

'His banner, I have not heard it'

Second, FMs ZHI and SHI also lend further support for the proposal involving functional categories. As can be observed from the attested data (7), when ZHI/SHI is present, it is always immediately preceded by a preposed element. So even if we hypothesise that the node for preposed DPs could either be on the edge of $v \mathrm{P}$ or CP (in order to account for (6)), this single node would still fail to accommodate two elements, i.e. the fronted DP and the FM immediately following it. If the assumption concerning functional projections is adopted, fronted nominal and pronominal elements can occupy the specifier node, while FMs may target the head of corresponding functional projections (Wang 2013).

(7) a. 王

何

卿

之

問

也?

(孟 子・萬章下)

Wáng

[hé

qīng] $]_{i}$

zhī

[vp wèn $\mathrm{t}_{\mathrm{i}}$ ] yě?

Your.Majesty what minister ZHI ask.about Decl

'What minister is Your Majesty asking about?'

b. 小国将君望傳·衰公 二十八年)

Xiăo guó jiāng jūn $n_{i}$ shì [vp wàng $t_{i}$ ]

small state will His.Majesty SHI expect

'Small states will expect His Majesty' 
Third, both FMs and prepositions target the head of functional projections. That is why there is a complementary distribution of FMs and prepositions. To be more specific, why an FM can only follow a fronted DP (7) but never coexists with a fronted PP (5) is because when the head node of a focus phrase is occupied by a fronted preposition, there is no position for the FM, and vice versa. Since a fronted wh-complement needs to occupy the specifier position of some functional projection in the tree structure and the wh-complement and the preposition need to stay in the same projection after movement, the only available landing site for both the preposition and any FM would be the relevant head position. As a consequence, a fronted preposition cannot co-occur with any FM.

Of course, it might be plausible that since fronting makers ZHI and SHI are pronominal elements (these morphemes can alternatively function as pronouns, as in (8a-b)), their lack of co-occurrence with PPs could be explained by the fact that these pronouns are entitydenoting, so they can only co-occur with nominals. However, as exemplified in (8c-d), ZHI actually can accompany pronominal DPs. Therefore, the fact that ZHI and SHI are entitydenoting cannot explain their absence in PP wh-questions, and the complementary distribution of FMs and corresponding prepositions must be caused by their common landing site, i.e. the head of functional projections.

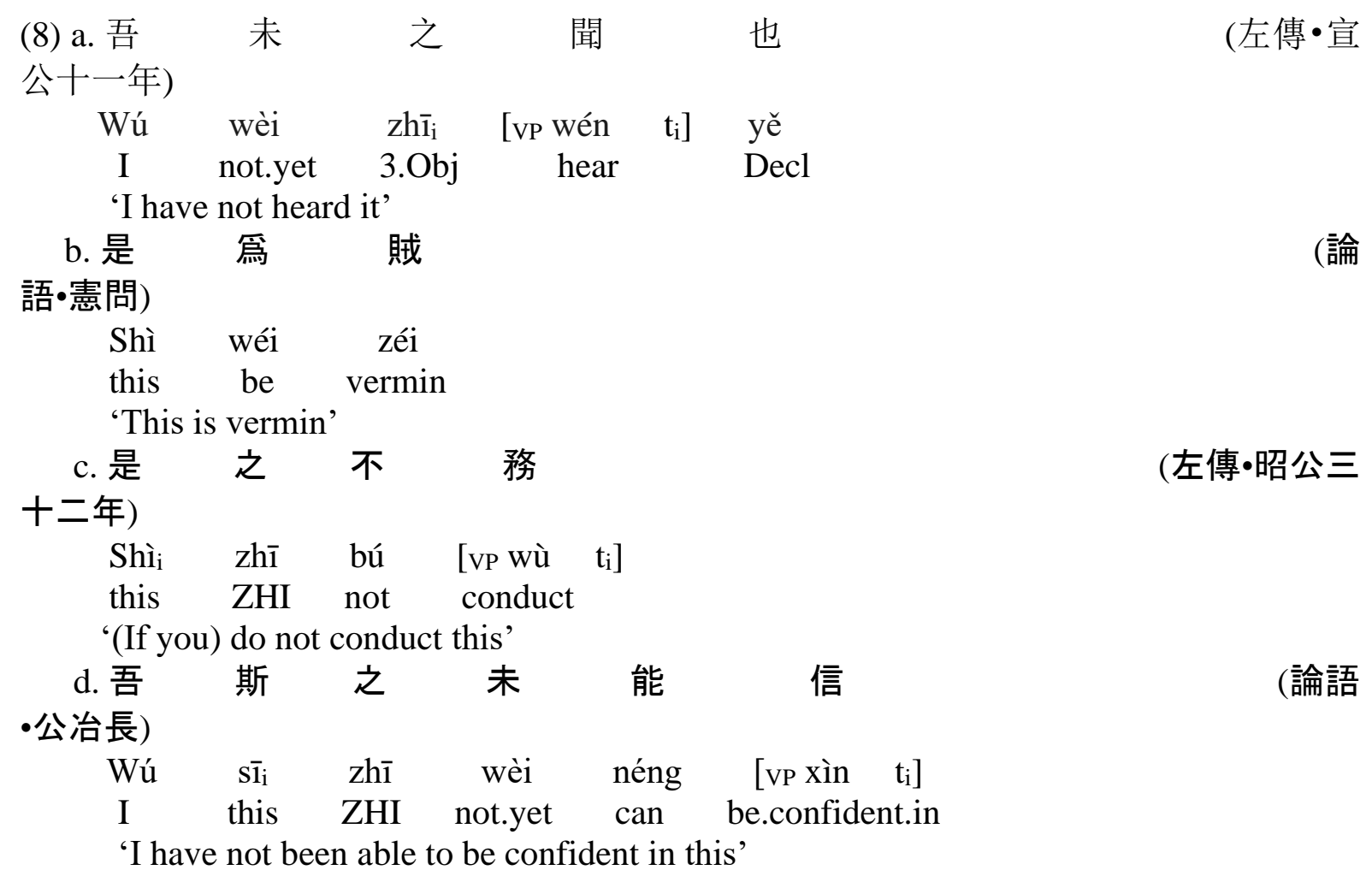

Returning to the approach of PP inversion followed by separate movement of $w h$ and $\mathrm{P}$, this argument accounts for four facts: 1) a preposed wh-element is higher than its corresponding preposition in the tree, 2) there is no intervening element between the preposed $w h$ and its corresponding preposition, 3) there is complementary distribution of FMs ZHI/SHI and prepositions, and 4) the derived order $w h$-P only occurs preverbally, but not postverbally.

For $w h$-PPs base-generated both preverbally and postverbally, their wh-complements undergo movement from the complement position to the specifier position within PPs, generating $w h-\mathrm{P}$. This is the first step: inversion within PP. The second step is the separate movement of $w h$ and P: $w h$ moves from [Spec, PP] to the specifier position of a functional projection, and then the preposition moves from $\mathrm{P}^{0}$ to the head of the functional projection. 
The existence of DP-P-VP structure generated from VP-P-DP justifies the separate movement of DP and P. There is no denying the fact that if the DP is a wh-phrase, it is unreasonable to claim that the inverted DP-P order is definitely caused by separate movement of $w h$-DP and $\mathrm{P}$, because the inverted order can be simply generated via obligatory $w h$ fronting. However, the relative order between PP and VP must be caused by separate movement of DP and P, because the first step, inversion, can only produce the VP-DP-P structure, not the final DP-P-VP structure (generated from VP-P-DP). For instance, in a noninterrogative sentence, the canonical order is VP-P-DP (9a); in a parallel interrogative sentence involving the same verb, when a $w h$ prepositional complement raises to a preverbal position, the preposition has to move to a preverbal position too, generating the derived $w h-\mathrm{P}-$ VP order (9b).

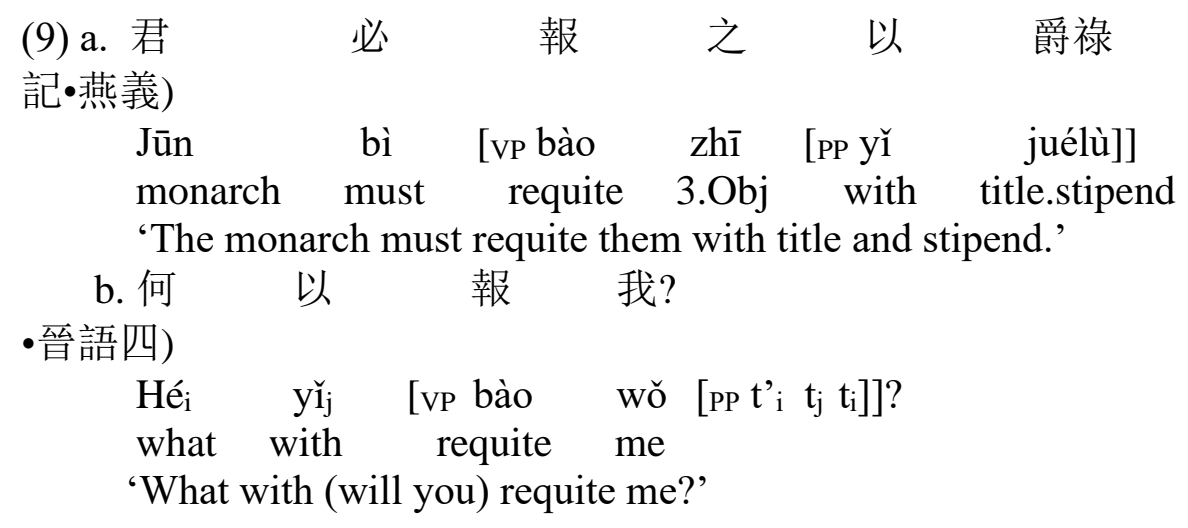

There is no denying the fact that these two steps overlap. First, they both lead to the wh-P order. Second, both steps guarantee that no element can intervene between wh and $\mathrm{P}$, which occupy the specifier and head position of the same projection respectively. Third, both steps ensure that *DP-P-X is not allowed, with X standing for preposition or FM.

However, I argue that both steps are necessary for wh-PPs, because each step has indispensable function(s): the first step allows the second step to take place, while the second step guarantees the right output and wh-licensing.

The first step, inversion within PP, allows the wh-complement to be fronted to a specifier position, so that $w h$ can further move to a higher specifier position. As for the second step, it generates the surface order $w h$-P-VP (derived from VP-P-wh). Additionally, moving $w h$ alone instead of embedding $w h$ within a prepositional phrase permits $w h$ to occupy a clausal specifier position, so as to get licensed.

Although both steps are indispensable for $w h$-PPs, they are not for non-wh-PPs. In theory, both steps could apply to non-wh-PPs, but the second step, or the second half of it, is often optional. Since the unique functions of the second step are to generate the surface order $w h-\mathrm{P}-$ VP from VP-P-wh and to ensure $w h$-licensing, as long as the right order has been derived and wh-licensing is not needed, (the second half of) the second step can be left out. For non-whPPs, wh-licensing is never required; if after the first step or the first half of the second step, the right output has been generated already, then the second step, or its second part, is omitted out of the economical principle. This fact indicates that these two steps are independent of each other.

First, the first step may happen even if the second step does not take place at all. For a nonwh-PP, after the prepositional complement undergoes movement within PP, if there is no motivation for this non-wh-DP to undergo further movement to a higher, functional projection, then it does not raise again after the first step, as (10). 


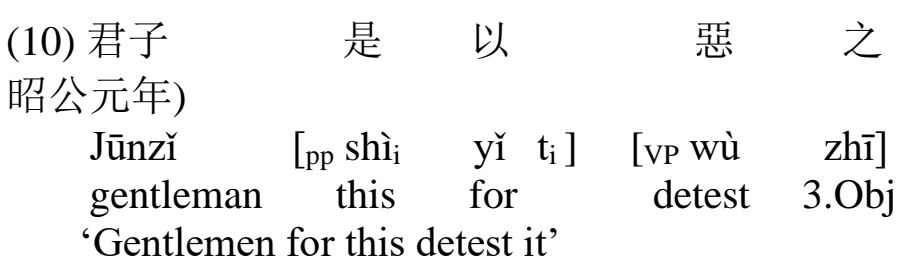

That is to say, the process of deriving DP-P-VP from P-DP-VP has completed through the first step, so no further movement is required. However, the movement of the DP from the complement position to the specifier position within PP, i.e. PP inversion, happens anyway as the first step, giving rise to the surface order DP-P-VP (10). This fact indicates that the two steps are independent of each other. The reason I conjecture that the first step has happened is due to the reversed DP-P order. If the inversion within PP did not happen and both DP and P stayed in situ, the order *P-DP-VP would be expected.

Second, after the first step takes place, the second step does not have to fully happen. After a non-wh-DP moves from the complement position to the specifier position within PP, it may further move to the specifier position of a functional projection, as the first part of the second step. The remaining part of the second step should be $\mathrm{P}$-movement from $\mathrm{P}^{0}$ to the head of the functional projection (for the motivation of P-movement, see below). However, the surface structure of DP-Mod-P-VP in (11) clearly shows that P-movement does not happen, otherwise a *DP-P-Mod-VP order would have been generated.

\begin{tabular}{|c|c|c|c|}
\hline $\begin{array}{l}\text { (11) 是 } \\
\text { 語•鄭語) }\end{array}$ & 可 & 以 & 少 \\
\hline & $\begin{array}{l}\text { kě } \\
\text { can }\end{array}$ & {$\left[\begin{array}{lll}\operatorname{PP} t^{\prime}{ }_{i} & \text { yri } & t_{i}\end{array}\right]$} & $\begin{array}{l}\text { [vP shāo } \\
\text { slightly }\end{array}$ \\
\hline
\end{tabular}

'(You) can slightly secure (it) with this'

The only feasible explanation for the structure DP-Mod-P-VP is that the non-wh-DP moves from the complement position within PP to [Spec, PP] and then to the Spec of the functional projection, yet the preposition stays in its base position $\mathrm{P}^{0}$ and never moves. That is to say, after the first step of separate movement takes place, the second step does not have to 'fully' happen. For non-wh-PPs, if the second half of separate movement, i.e. P-movement, happened, ungrammatical structures would be generated. It is notable that such an observation only applies to non-wh-PPs: for a preposition in a $w h$-PP, it must raise to the head of some functional category so as to stay in the same projection with its $w h$-complement.

Therefore, I conclude that the two steps of DP-P are independent of each other: the first step can take place without the (full) completion of the second step. The approach of inversion followed by separate movement applies well to non-wh-PPs, but in some cases the second step is (partially) optional.

There is no denying the fact that when only the first step takes place, yet the second step which is optional does not happen, this account seems to coincide with the above-mentioned approach of mere PP inversion. However, even if the approach of mere PP inversion seems to be able to explain certain non-wh-PPs, it fails to apply to all non-wh-PPs: for structures like DP-Mod-P-VP (as in (11)), apart from PP inversion, the non-wh-DP must move further to a functional projection higher than ModP. Besides, the approach of mere PP inversion cannot account for $w h$-PPs at all. Therefore, in order to find a unified approach that can explain both $w h$ - and non-wh-PPs, I adopt the approach of PP inversion followed by separate movement of $\mathrm{DP}$ and $\mathrm{P}$.

Although the approach of inversion followed by separate movement seems to be the most feasible strategy to account for $w h$-P, there are three points that need to be discussed: 1 ) 
constituency of $w h$ and P, 2) the locality problem of PPs, and 3) motivation for P-movement.

The constituency question of $w h$ and $\mathrm{P}$ denotes that the preposition and its $w h$-complement form a constituent before movement, but they fail to form one after movement. I argue that this constituency mismatch is the natural consequence of the language per se.

First, there is a complementary distribution of FMs and PPs (cf. (5) and (7)). If the fronted $w h$-complement and the fronted preposition still stayed in the same projection, both $w h$ and $\mathrm{P}$ would occupy the specifier position of a functional category, so the head position of the functional projection could be occupied by a FM ZHI or SHI. However, wh-P never cooccurs with a FM, whether above or below negation, because the construction $* w h-\mathrm{P}-\mathrm{FM}$ is never attested.

Second, I assume that LAC has a licensing requirement for $w h$-phrases, i.e. $w h$ has to be licensed in a clausal specifier position in the medial domain, monitored by the language per se, like the fact that $w h$ in modern English has to be licensed in [Spec, CP]. Although placing preposed $w h$ and $\mathrm{P}$ into the same node does not affect the requirement that $w h$ has to land in the medial domain, it fails to allow wh to occupy a clausal specifier position, and hence no wh-licensing.

Third, the unavailability of *P-DP-VP derived from VP-P-DP concerning non-wh-DPs justifies that a preposition and its complement cannot form a constituent after movement. I propose that unlike $w h$-PPs that always end up in an inverted $w h$-P order due to obligatory wh-fronting, inversion within non-wh-PPs is optional, and both P-DP and DP-P are permitted. Since inversion, as the first step, is optional for a non-wh-PP, the second step, PP movement, should be able to take place independent of the first step. For a non-wh-PP base-generated postverbally and fronted to a preverbal position, if inversion did not happen but $\mathrm{P}$ and DP still formed a constituent, we would expect (long-distance) PP movement only, hence an order PDP-VP. However, the order *P-DP-VP (derived from VP-P-DP) is never attested. Therefore, the wrong prediction concerning non-wh-PPs helps to show that it is impossible for $w h$ and $\mathrm{P}$ to still form a constituent after movement.

Fourth, the availability of the construction DP-Mod-P concerning non-wh-PPs (see (11) above and (13) below) helps to rule out the possibility of $w h$ and P staying as a constituent after movement. For a non-wh-PP, if DP and P stayed in the same constituent, the relative order between the PP and the modal of ability or the modal auxiliary verb would be DP-PMod or Mod-DP-P. Nonetheless, the order attested is DP-Mod-P, indicating that the requirement of $w h$ and $\mathrm{P}$ forming a constituent after movement is infeasible.

The second question, the locality problem of PPs, is that for a wh-PP, its movement may potentially violate HMC, CED or both.

First, when the wh-complement of a goal PP follows a ditransitive verb and a theme argument, it undergoes long-distance movement from a postverbal position to a position above $v \mathrm{P}$, but the movement of the preposition seems to violate the HMC that head movement cannot 'skip' an intervening head (Travis 1984, Roberts 2001). As can be seen from the tree in (3c), in order to move into the final position which does not properly govern it, the head preposition 乎 $h \bar{u}$ 'to' has to skip over a governing head, i.e. the verb 比 $b \grave{\imath}$ 'to compare', violating the HMC.

Second, when a $w h$-PP is generated preverbally, both $w h$ and $\mathrm{P}$ front out of the PP to higher positions, so it seems that if the $w h$-PP was an adjunct, the P-movement and whpreposing out of this phrase would violate the CED that a phrase may be extracted out of a domain only if it is properly governed (Huang 1982, Huang et al 2009).

Third, when an adjunct wh-PP is base-generated postverbally yet the surface structure is wh-P-VP, there must be movements of both the preposition and $w h$ from postverbal to preverbal positions: the fronting of $\mathrm{P}$ may violate the HMC and CED, and the fronting of $w h$ may violate the CED. In (12) involving wh-PP adjuncts (different from (3) involving a wh-PP 
argument), the interrogative sentences and their following non-interrogative counterparts form pairs of parallel questions and answers. Since PPs in the answers are base-generated postverbally, it is reasonable to assume that the canonical order of the corresponding questions is also VP-PP. To obtain the surface structure, both the head preposition and its whcomplement need to move to preverbal positions. In the tree diagram in (12c) which indicates (12a), the movement of the head preposition would violate the HMC and CED, and the fronting of the preposition and its $w h$ prepositional complement would violate the CED if the PP was analysed as an adjunct island.

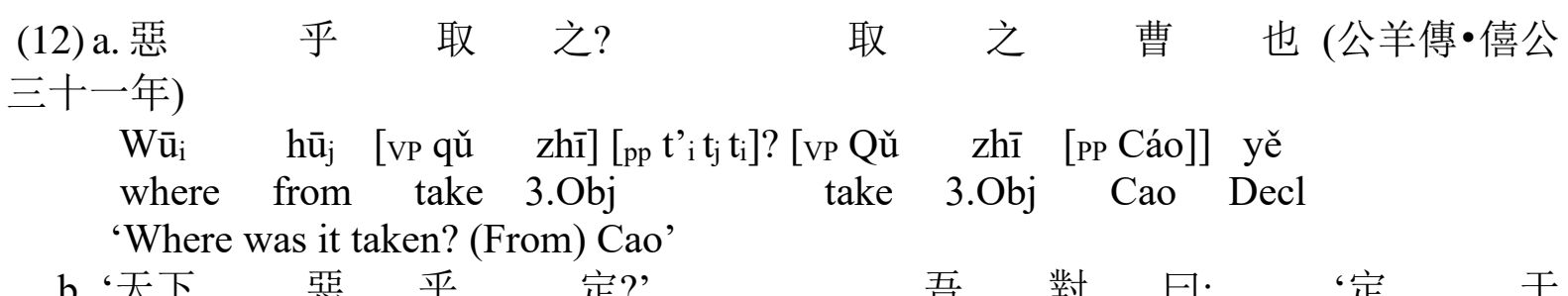

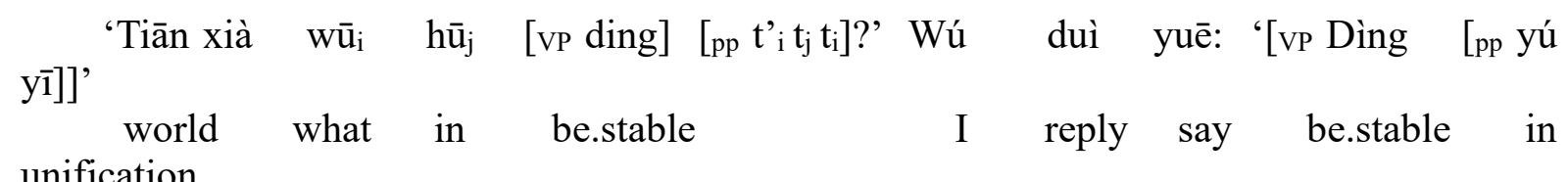
unification

“"How can be world be stable?" I replied: "(The world) is stable out of unification"”

\section{梁惠王上)}

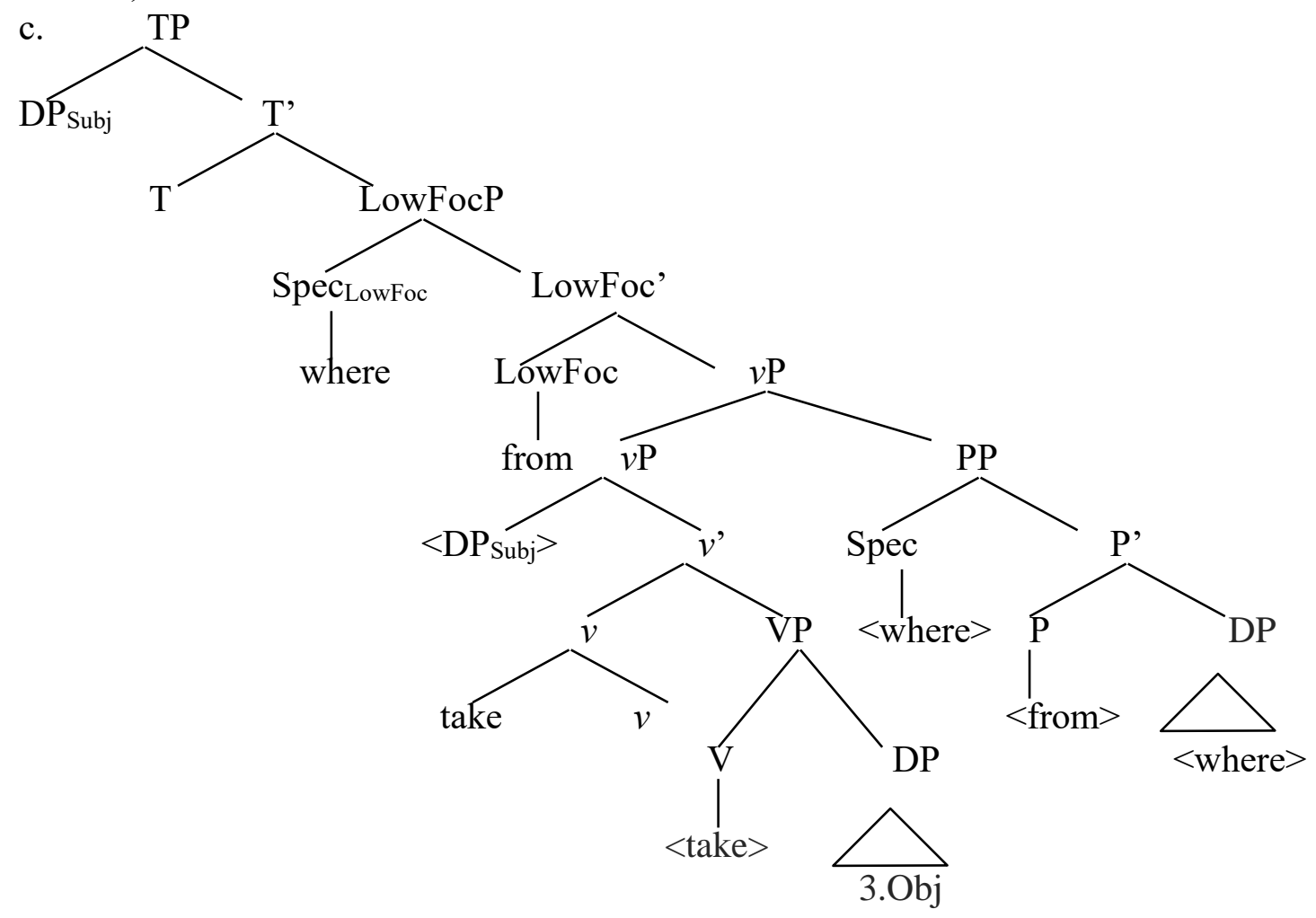

I suggest that the movement of head prepositions in LAC may be analysed in line with Roberts' $(1991,2001)$ excorporation account. For the preposition base-generated after VP in LAC, it may be analysed in a similar way to clitic climbing. The head preposition first incorporates to a $\mathrm{V}^{0}$, and then moves alone to the head position of a functional projection through excorporation which is successive-cyclic, non-roll-up movement of a head 'passing 
through' the edge of another head. Excorporation in LAC is reduced to the HMC, and the adjunction of the preposition takes place through functional heads.

To resolve the problem regarding the CED, I follow Stepanov $(2001,2007)$, who argues that the complement/non-complement distinction should be further scrutinised, and thematic adjuncts must be separated from structural adjuncts. The criterion for determining structural argumenthood and adjuncthood lies in the uninterpretable features in the label of the element being Merged. If the element does not contain any uninterpretable feature, it enters the structure by adjunction, hence being subject to the Late Adjunction Hypothesis that specifies a strict timing of the application of substitution and adjunction Merge: any adjunction must take place postcyclically after all substitution Merge has applied. Substitution Merge simply creates new structures on top of the set of c-command relations, but never changes it. Adjunction Merge, however, results in the change in the set of c-command relations inside the existing structure. This thematic adjunct, therefore, is also a structural adjunct. By contrast, if an element involves any uninterpretable feature in its label, i.e. structural Case or a $w h$-feature, it enters the structure by substitution, thus being a structural argument. If the prepositional complement has a $w h$-feature, it is matched by Agree on the preposition, so the $w h$-feature is visible in the label of the entire PP. Therefore, a $w h$-PP is a thematic adjunct, but a structural argument, entering the structure by substitution (as a specifier) cyclically. Consequently, a $w h$-PP is subject to $w h$-fronting, a cyclic $w h$-dependency.

In LAC, a thematic adjunct $w h$-PP has a visible $w h$-feature as an uninterpretable feature, so it acts as a structural argument and enters the structure by substitution. Since the substitution Merge of a structural argument applies before adjunction, extraction out of the $w h$-PP adjunct is expected. This 'eclectic' account also explains extraction out of subjects of ECM verbs in LAC. Since a subject always has an uninterpretable feature (structural Case) in its label, it enters the structure by substitution and hence cyclically, so it can undergo movement.

In respect of the motivation for P-movement, it could be that LAC is an 'intermediate' Pstranding language that permits P-stranding for non-wh-PPs, but the preposition somehow is prohibited to be separated from its fronted $w h$-complement. Therefore, after a prepositional complement raises to a higher position motivated by obligatory $w h$-fronting, the preposition has to raise, or be attracted, to a higher position too, so as to stay adjacent to its complement in the same projection and share some common feature. Since the landing site of the $w h$ prepositional complement is the Spec of a functional projection, the consequence is that $w h$ and $\mathrm{P}$ cannot form a constituent anymore and $\mathrm{P}$ ends up to be lower than $w h$. Of course, the nature of LAC being an intermediate P-stranding language only constrains interrogative constructions but not non-wh-phrases. As a consequence, if a DP-X-P order is generated via PP inversion followed by DP-movement, DP and P do not stay adjacent with each other in the same projection, as in (13).

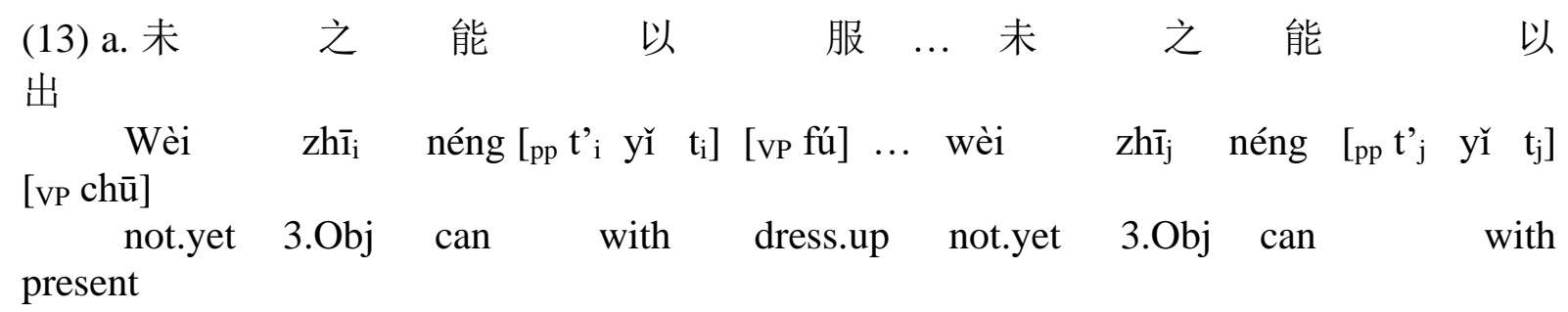
with it'

'(I) have not been able to dress up with it...(I) have not been able to present (sacrifices) 二十五年) 


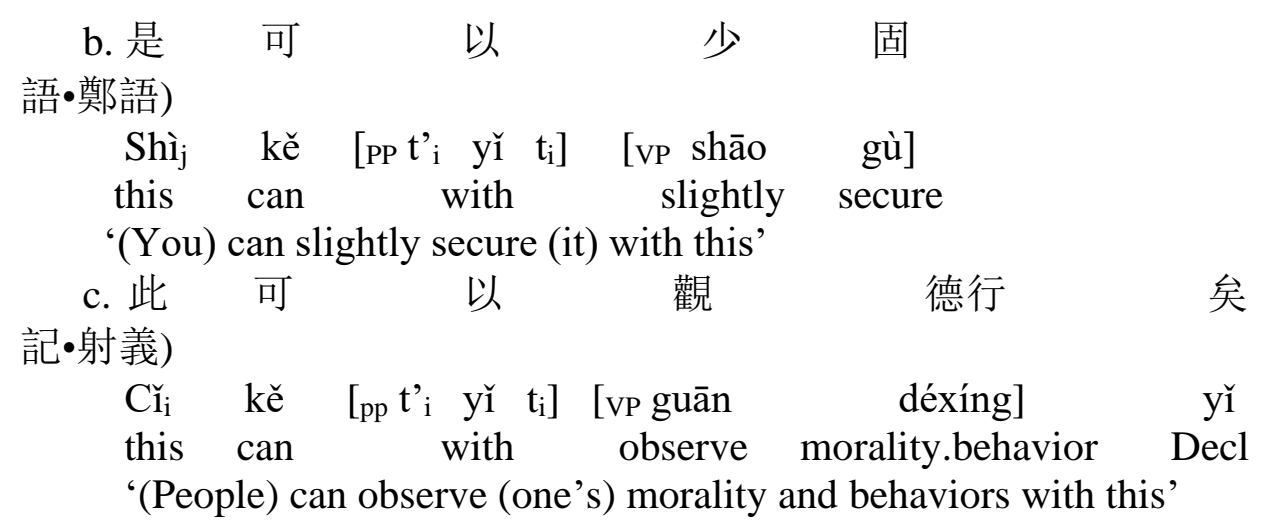

\section{The Intervention Effect of Negation}

The Intervention Effect in the sense of Beck (1996) and Beck and Kim (1997) refers to the fact that a barrier may not intervene between a question existential operator (Q-operator) and a function variable bound by that Q-operator. Such a blocking effect applies to $w h$-in-situ, the stranded restriction of $w h$-constituents moving overtly, as well as wh-scope marking structures. In modern Mandarin, focus induces the Intervention Effect on $w h$-DPs, whereas negation or quantification is allowed to occur between a Q-operator and an in-situ wh-DP bound by that Q-operator. Additionally, there is a repair strategy to circumvent the Intervention Effect in Mandarin by means of raising in situ $w$-items to a position preceding the focus-induced barrier. Feature movement is sensitive to the Intervention Effect, yet phrasal movement is not. Since $w h$-nominals in Mandarin undergo phrasal movement yet $w h$ adverbials undergo feature movement, only the latter is subject to the Intervention Effect triggered by quantification and negation (Pesetsky 2000, Kim 2002a, 2002b, 2006, Soh 2005).

In LAC, negation displays the Intervention Effect on wh-arguments and wh-adverbials. Owing to their focal nature, preposed non- $\mathrm{D}$ (iscourse)-linked $w h$-complements within $v \mathrm{P}$ as well as $w h$-adverbials base-generated postverbally or between negation and $v \mathrm{P}$ should target the Low focus position below negation. However, these $w$ h-arguments and adverbials are subject to the Intervention Effect triggered by negation. As a consequence, whenever there is a negator, a wh-constituent must raise to the High focus position c-commanding negation so as to circumvent the Intervention Effect and realise Q-binding.

Before discussing the presence of the Intervention Effect of negation on non-D-linked nominal wh-phrases in the Low focus position, I justify the existence of the Low focus position in LAC. To begin with, the nature of this position is focal. I follow a proposal that the position of focus in an answer correlates with the questioned position in a wh-question (Rooth 1996). Example (14) is constituted of a question and answer pair, and the answer contains a morpheme 唯 WEI that indicates assertive modality and is frequently translated into 'only' (Djamouri 2001, Meisterernst 2010). Since the answer in (14) involves WEI introducing an only-focus, it is reasonable to assume that the corresponding $w h$-phrase in the question also occupies a focus position.

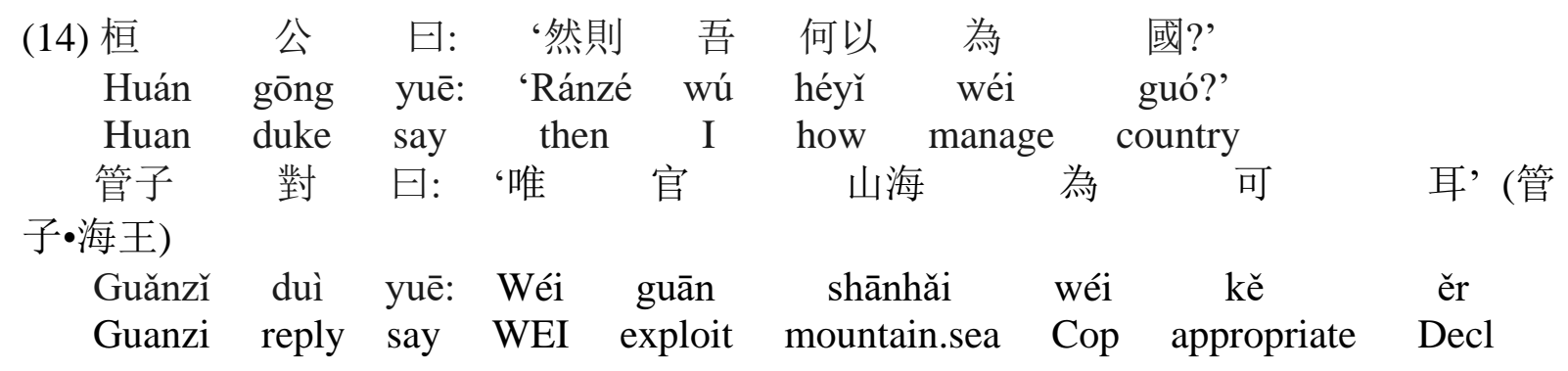


'The Duke of Huan asked: “Then how do I manage the country?" Guanzi replied: "It is only

exploiting mountains and seas that is appropriate",

There is a difficulty to directly prove the location of the Low Focus position: without the presence of negation, it is impossible to tell the Low focus position apart from the High focus position, yet in the context of negation, wh-phrases can never appear below negation, as observed by Aldridge (2010) and many others. To address this problem, I draw on a key adverb 獨 $d \dot{u}$ ' alone' that can diagnose the position where negation is generated. The adverb $d u ́$ always immediately precedes negation, and no element can intervene between $d \dot{u}$ and the following negator. That means if a wh-element follows $d \dot{u}$, then this $w h$ must follow the position of negation accordingly. Therefore, $d u$ is a crucial diagnostic element to decide the relative order between $w h$-phrases and negation, even without the presence of negators (Wang 2015). Example (15a) shows that dú immediately precedes a negator; in (15b) where $d u$ is present while negation is not, $w h$ follows $d \dot{u}$, so that means it follows negation as well, occupying the Low focus position.

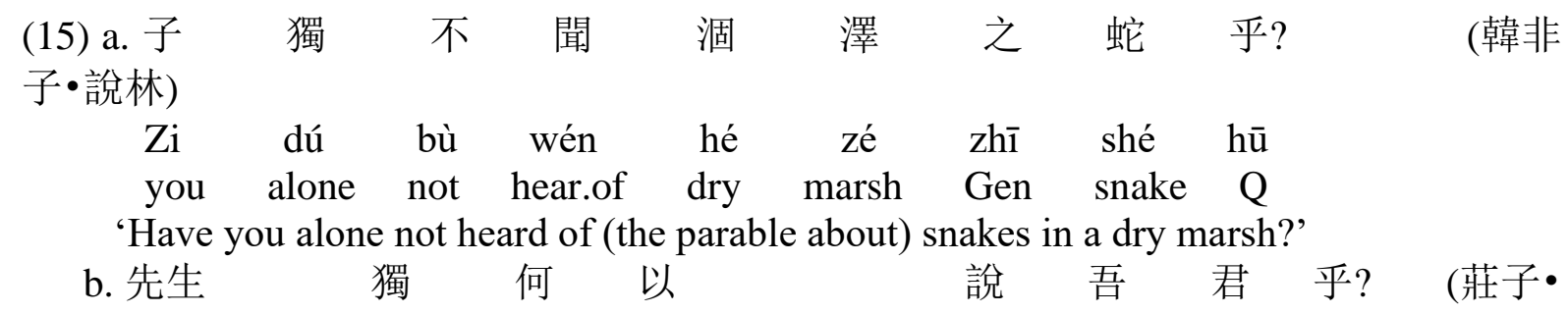
徐無鬼)

Xiānshēng dú hé ${ }_{i} \quad y_{1}{ }_{j} \quad\left[{ }_{p P} t^{\prime}{ }_{i} t_{j} t_{i}\right]$ [vp yuè wú jūn] hū? sir(you) alone what with please my lord Q 'How did you alone please my lord?'

To justify the Intervention Effect of negation on non-D-linked nominal wh-phrases in the Low focus position, I refer to the second clause in (16a) where a wh-object 何 hé 'what' lands in a position preceding negation. As a non-D-linked $w h$-DP, hé is supposed to land in a focalised position; moreover, its VP-internal base position indicates that it should move to the Low focus position. However, when the wh-word appears in the Low focus position, it is ccommanded by a negator 不 bù that is an intervener, so hé needs to move to a position over negation in order to be bound by a Q-operator. Since hé is non-D-linked, this position cannot be the External/Internal topic position, but the High focus position which is supposed to accommodate 'high' reason adverbials exclusively. Therefore, I argue that when ccommanding a non-D-linked $w h$-DP that is supposed to land in the Low focus position, the Intervention Effect of negation applies to the wh-nominal and triggers its fronting to the High focus position. Consequently, hé in two sentences of (16a) occupies distinct positions. The tree diagram of the second question in (16a) is presented in (16b).

\begin{tabular}{|c|c|c|c|c|c|c|c|c|}
\hline $\begin{array}{l}\text { (16) a. 然则 } \\
\text { 子•秋水) }\end{array}$ & 我 & 何 & 爲 & 乎? & 何 & 不 & 爲 & 乎? \\
\hline $\begin{array}{l}\text { Ránzé } \\
\text { then }\end{array}$ & $\begin{array}{c}\text { wǒ } \\
\text { I }\end{array}$ & $\begin{array}{l}\text { hé }_{i} \\
\text { what }\end{array}$ & $\begin{array}{c}\text { [vp wéi } t_{i} \text { ] } \\
\text { do }\end{array}$ & $\begin{array}{l}\text { hū? } \\
\text { Q }\end{array}$ & $\begin{array}{l}\text { Hé }_{j} \\
\text { what }\end{array}$ & $\begin{array}{l}\text { bù } \\
\text { not }\end{array}$ & $\begin{array}{c}\text { [vP wéi } t_{j} \text { ] } \\
\text { do }\end{array}$ & $\begin{array}{l}\text { hū? } \\
Q\end{array}$ \\
\hline
\end{tabular}




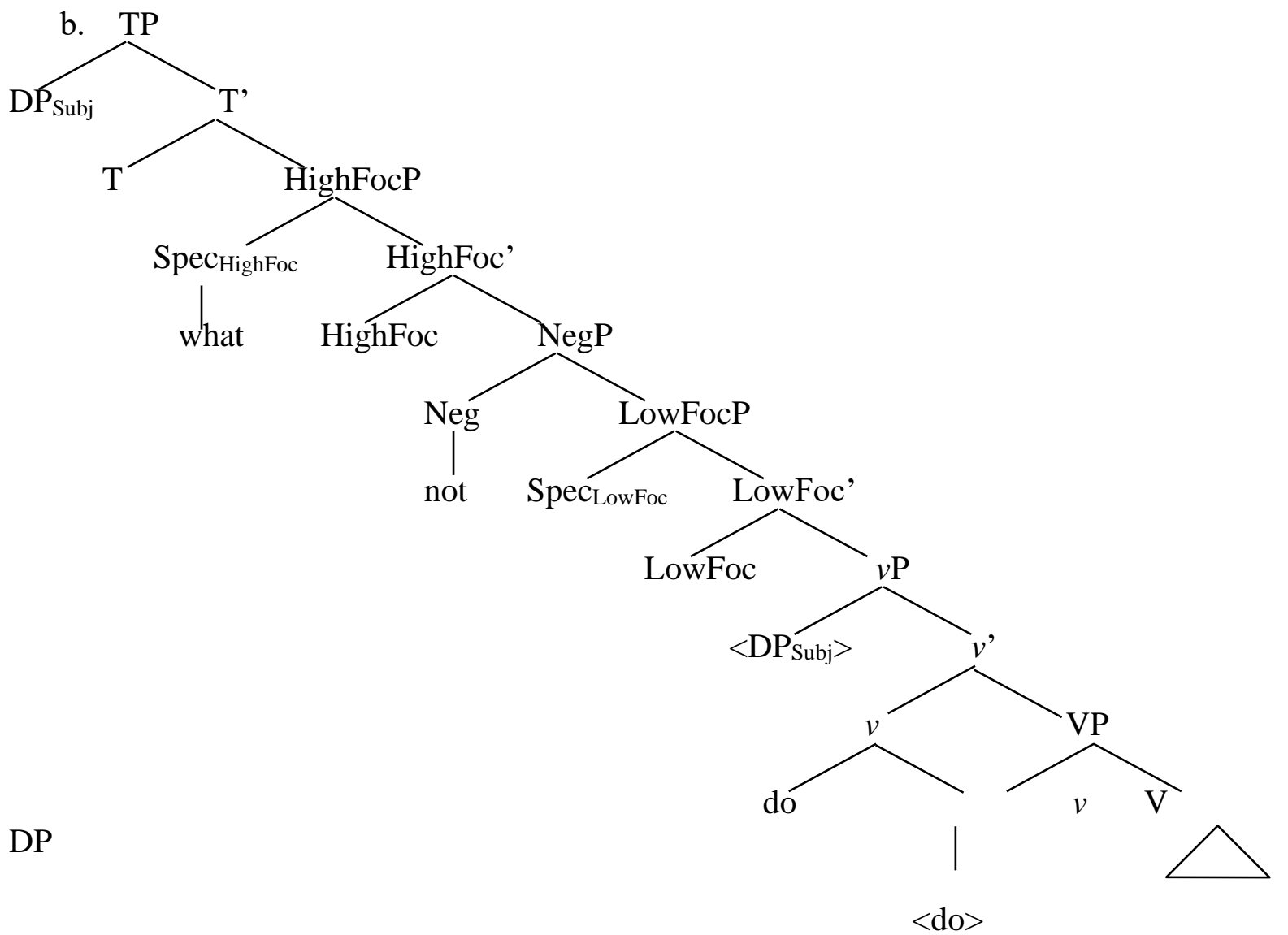

$<\mathrm{DP}_{\text {HighFoc }}>$

Analogous to nominal $w h$-phrases, adverbial $w h$-phrases are always above negators in the context of negation, and no examples of $* \mathrm{Neg}$ (VP) $w h$ (VP) are ever attested. This observation is not surprising for 'high' reason $w h$-adverbials whose base position is already above negation. However, for a non-reason wh-adverbial base-generated postverbally or preverbally but below negation, it cannot be bound by a Q-operator, owing to the intervening negator. Consequently, this $w h$-adverbial must adopt a repair strategy by fronting to the High focus position that is not c-commanded by negation. Parallel to the pre- and postverbal base positions, the Low focus position cannot accommodate $w$-adverbials either, because it is also c-commanded by negation. 
In LAC, location, source and manner $w h$-adverbials are subject to the Intervention Effect of negation.

First, for locative adverbials base-generated postverbally, their wh-complements are expected to move to a position between negation and $v \mathrm{P}$. In (17a) where negation is absent, the wh-adjunct base-generated postverbally lands in a position following the aspectotemporal adverb 將 jiāng (as proposed by Meisterernst (2008)) which I argue to intervene between the High focus position and the Low focus position (as shown in (2)), so this whadjunct must land in the Low focus position below negation. However, in the context of negation, the locative adjunct 安 $\bar{a} n$ 'where' in the second clause of (17b) moves overtly from its base position to the High focus position across the negator. It can be seen that negation functions as a barrier for the Q-binding of wh-adverbials base-generated postverbally: wh would have targeted the Low focus position if there was no Intervention Effect of negation. However, the Low focus position cannot accommodate the wh-adjuncts, as it is c-commanded by the negator, parallel to the base position. So instead of raising to the Low focus position and still being c-commanded by the intervener, wh-elements target the High focus position ccommanding the negative intervener.

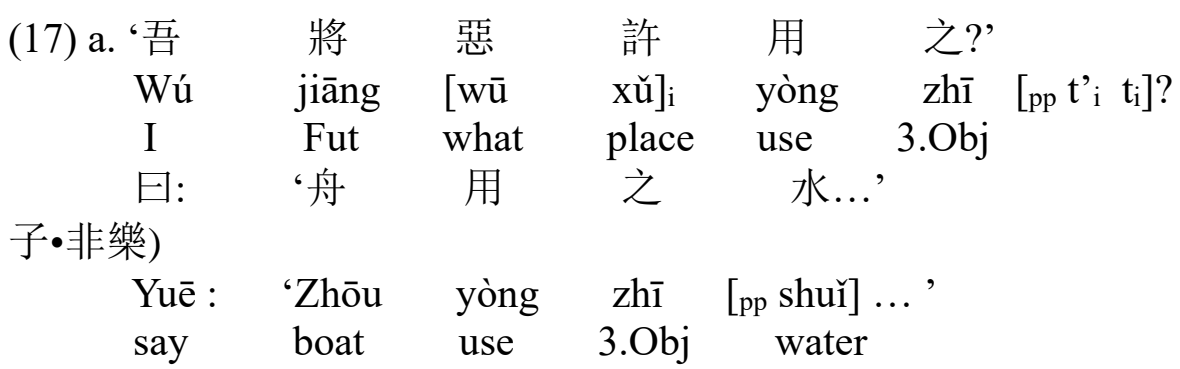

“(In) what place will I use them?" (Mozi) said: "Boats, (you) use them (on) the water..."

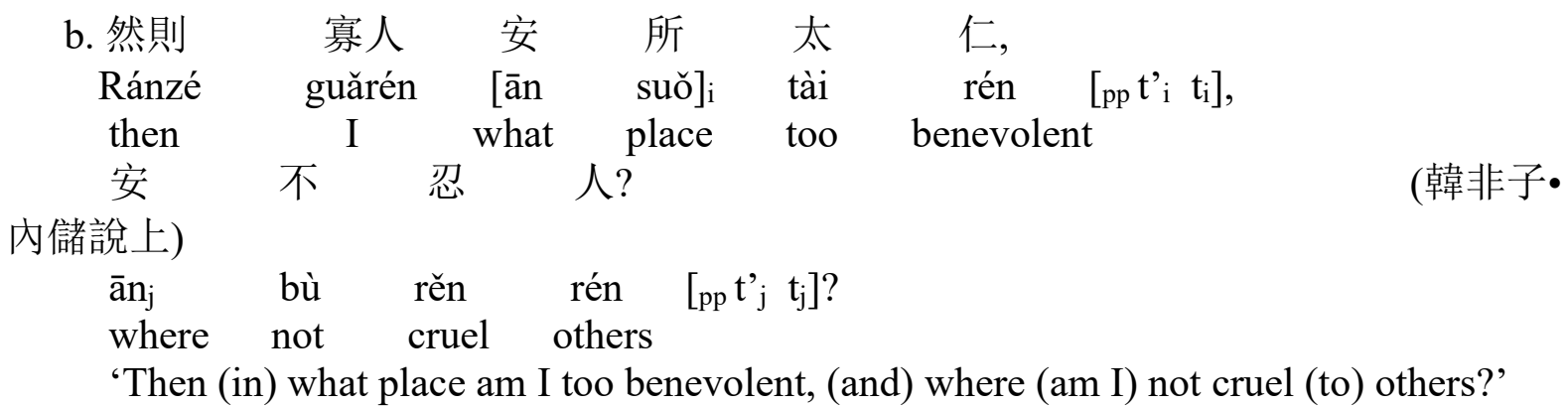

In order to show that the locative $w h$-adjunct in (17a) is base-generated postverablly, I draw on its non-interrogative counterpart accompanying the same verb. Example (18) contains a non-interrogative locative adverbial that does not undergo movement, so the canonical VP-PDP order lends support to the claim that the locative $w h$-adjunct in (17a) is base-generated postverbally. Additionally, the postverbal base position of the wh-PP in the question can be further justified by the non-wh-PP in the parallel answer in (17a).

$\begin{array}{cccccc}\text { (18) 將 } & \text { 欲 } & \text { 用 } & \text { 之 } & \text { 於 } & \text { 天下 } \\ \text { 谷子•飛箝) } & & & & & \\ \text { Jiāng } & \text { yù } & \text { yòng } & \text { zhī } & \text { [pp yú } & \text { tiānxià] } \\ \text { Fut } & \text { want } & \text { use } & 3 . \text { Obj } & \text { in } & \text { world }\end{array}$

'(If one) will want to use it in the world' 
Second, source PPs are base-generated postverbally, and their wh-complements are expected to target a landing site between negation and $\nu$ P, i.e. the Low focus position (19a). However, in the presence of negation as a barrier, source PPs always appear in a position preceding the negator (19b), viz. the High focus position. The canonical order of the interrogative sentence in (19a) is illustrated by its non-interrogative counterpart involving the

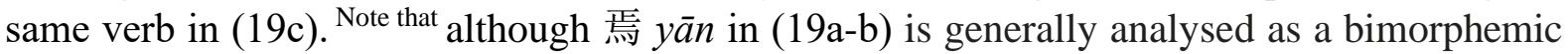
fusion word whose initial consonant is a preposition, this fact does not invalidate the wh-P order, as obligatory $w h$-fronting in LAC only applies to prepositions and $w h$-phrases when they are independent, rather than being infused into one character.

(19) a. 仲尼焉學? (論) 語•子張)

Zhòngní yān $n_{\mathrm{i}} \quad$ [vp xué] $\left[\mathrm{pp} \mathrm{t}^{\prime} \mathrm{t}_{\mathrm{i}}\right]$ ?

Zhongni where study

'(From) where does Zhongni study?'

b. 夫子 焉 不 學?

(論 語•子張)

Fūžr yān ${ }_{i}$ bù [vp xué] $\left[p p t^{\prime}{ }_{i} t_{i}\right]$ ?

Confucius where not study

'(From) where does Confucius not study?' 仲春紀)

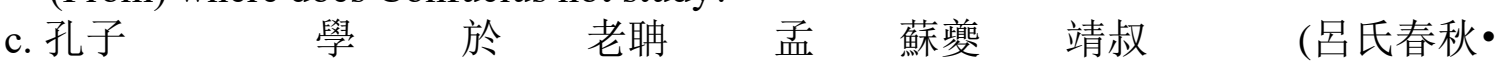

Kŏngzǐ [vp xué] [pp yú lăodān mèng sūkuí jìngshū]

Confucius study from Laodan Meng Sukui Jingshu

'Confucius studied from Laodan, Meng Sukui and Jingshu'

Third, wh-phrases functioning as adverbials of manner are also subject to the Intervention Effect of negation. Without negation, wh-adverbials of manner may appear in a position below negation. In (20a), a manner adverbial 焉 yān 'how' follows the key diagnostic element $d \dot{u}$ that always immediately precedes negation, so despite the absence of negation, $y \bar{a} n$ is predicted to target the specifier node of the Low Focus projection below NegP, triggered by obligatory wh-preposing. Nevertheless, in the context of negation, manner adverbials must appear in a position c-commanding negators. In (20b), a manner adverbial 奈 何 nài hé 'how' has to precede the negator, occupying the High focus position. Note that I treat the manner adjunct in the interrogative sentence in (20a) as being base-generated preverbally between negation and $\nu \mathrm{P}$, as can be shown by its non-interrogative counterpart in (20c) involving the same VP and the PP-VP canonical order.

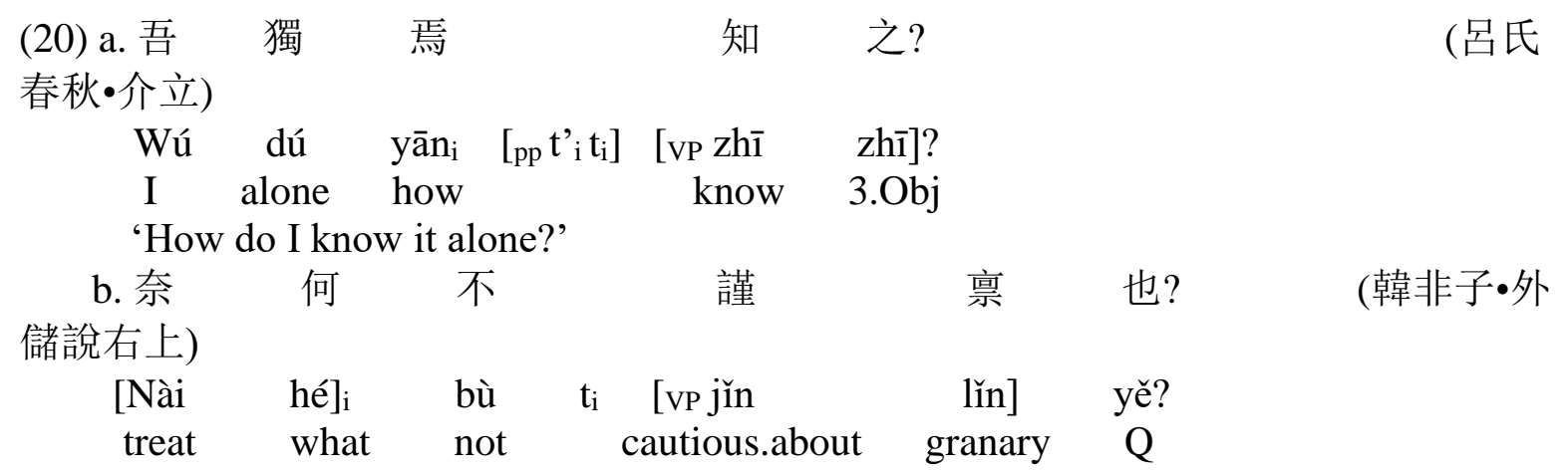


'How (can one) not cautious(ly) (protect) the granary?'

c. 臣政知之

子・哀公)

$\begin{array}{lcrcc}\text { Chén } & \text { [pp yǐ } & \text { zhèng] } & \text { [vP zhī } & \text { zhī] } \\ \text { subject(I) } & \text { through politics } & \text { know } & 3 . \text { Obj } \\ \text { 'I know it through politics' }\end{array}$

Now we can conclude that the High focus position is expected to permit reason whadverbials exclusively, but due to the Intervention Effect of negation, the following two types of wh-phrases which are expected to front to the Low focus position must also raise to the High focus position in the context of negation: VP-internal wh-nominals, as well as $w h$ adverbials base-generated between negation and $v \mathrm{P}$ or postverbally.

I propose that there are three requirements for the Intervention Effect: 1) interrogativity of $w h$-items, 2) possibility of feature wh-movement, and 3) locality restriction. If and only if all three conditions are satisfied, the Intervention Effect can take place.

The first condition of the Intervention Effect in LAC is that wh-constituents have to be interrogative. In Example (21), a wh-indefinite follows the negator without moving to a preceding position, thus it consequently becomes a negative polarity item (NPI). However, this instance involves obligatory $w h$-in-situ, namely a wh-constituent acting as the second complement of ditransitive verbs 奈/若/如 nài/ruò/rú, so it is difficult to judge which factor circumvents the Intervention Effect: the non-interrogative interpretation, or obligatory $w h$-insitu, or both.

$\begin{array}{cccccccc}\text { (21) 孤 } & \text { 無 } & \text { 奈 } & \text { 越 } & \text { 之 } & \text { 先 } & \text { 君 } & \text { 何 (國語・吳語; Aldridge } \\ \begin{array}{c}2010: 25) \\ \text { Gū }\end{array} & \text { wú } & \text { nài } & \text { [yuè } & \text { zhī } & \text { xiān } & \text { jūn] } & \text { hé } \\ \text { I } & \text { not.have } & \text { treat } & \text { Yue } & \text { Gen } & \text { former } & \text { lord what }\end{array}$ 'There was nothing I could do about the former lord of Yue'

The effect of non-interrogativeness is more self-evident if we take a look at (22). In this example, an NPI $w h$-word has been fronted within an embedded clause, but the licenser is in a higher domain, so the focalised wh-element is still below negation; in other words, the blocking effect does not apply to this $w h$-indefinite.

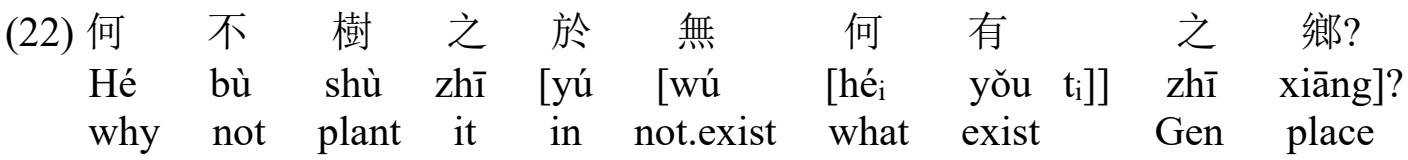

'Why don't you plant it in a place where there isn't anything?'

2010: 26)

(莊子・逍遙遊; Aldridge

The fact that the Intervention Effect of negation does not apply to $w h$-indefinites is not surprising: the blocking effect in the sense of Beck (1996) and Beck and Kim (1997) requires a Q-operator and a function variable bound by that Q-operator. When functioning as a polarity item, a wh-constituent does not involve Q-binding, so it may occupy a position lower than negation (which is a barrier for an interrogative wh-phrase as a function variable), without undergoing further fronting. This explanation also applies to the observation that negation in LAC does not affect a non-wh-constituent: a pronominal object may raise to a focalised position below negation (23a), or stay in its VP-internal base position (23b). 
(23) a. 若 子 不我信

•楚語下)

$\begin{array}{lcllrr}\text { Ruò } & \text { zì } & \text { bù } & \text { wǒi } & {\left[\begin{array}{ll}\text { vp xìn } & t_{i}\end{array}\right]} \\ \text { if } & \text { you } & \text { not } & \text { me } & \text { trust } & \end{array}$

'If you do not trust me'

b. 晋人 用

之

(國語

・楚語上)

Jìn rén [vp yòng zhī]

Jin person employ 3.Obj

'Jin people employed him'

The second condition of the Intervention Effect is that wh-constituents should be permitted to undergo feature movement, instead of being restricted to covert phrasal movement.

In LAC, if an XP $[+w h]$ can front, the fronting is either introduced by clause-internal overt movement, or the $[+w h]$ feature is interpreted by feature movement. The latter is subject to the Intervention Effect, yet the former is not. If an XP $[+w h]$ cannot front, namely, under the situation of obligatory $w h$-in-situ, it is interpreted by feature movement.

I hypothesise that $\mathrm{Q}$ is around $\mathrm{CP}$ and negation intervenes between $\mathrm{Q}$ and a $w h$-XP. When feature movement applies, the interpretation of the $w h$-XP is blocked by the Intervention Effect, so a wh-phrase that has an option to front will front to a focus position driven by [+Foc] feature, within which $w h$ undergoes feature movement to Q, as in (24).

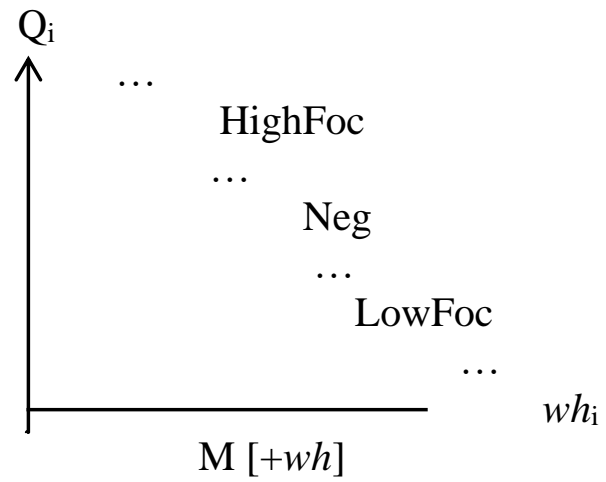

M: feature movement

In terms of overt phrasal movement, if a $w h$-phrase moves to a focus position above Neg (the High focus position) due to focus feature and stops there, then it is interpreted via feature movement that is subject to the Intervention Effect. In this situation, no ungrammaticality results, as in (25).

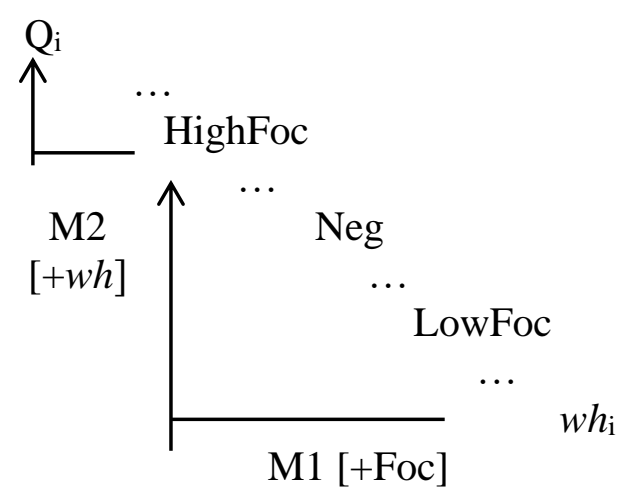


M1: overt phrasal movement; M2: feature movement

However, if a $w h$-XP underwent overt phrasal movement to a position lower than negation, i.e. the Low focus position, the sentence would be ungrammatical. Such a prediction is borne out, as no such data is ever attested.

$(26) *$

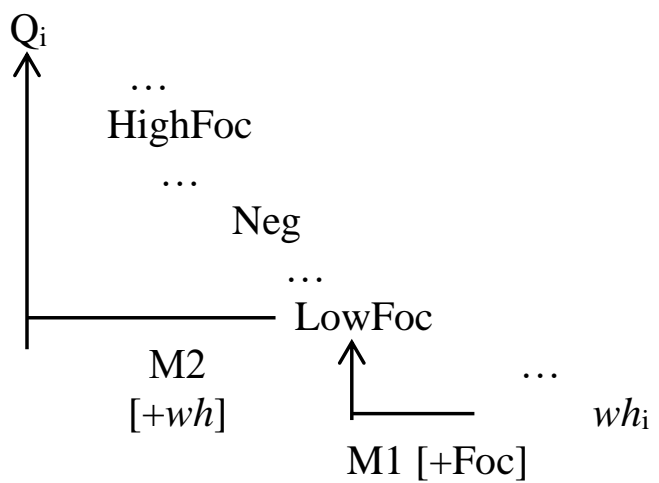

M1: overt phrasal movement; M2: feature movement

Consequently, wh has to move again to a position above negation and get the interpretation via feature movement, and this is the repair strategy. A wh-XP first fronts overtly to a focus position below negation driven by [+Foc] feature; since in this position the Q-binding is blocked by the intervening negation, the wh-XP has to raise overtly again to another focus position above negation, also driven by $[+\mathrm{Foc}]$ feature. After landing in its final position which is the High focus position above negation, the wh-XP is interpreted by feature movement (27).

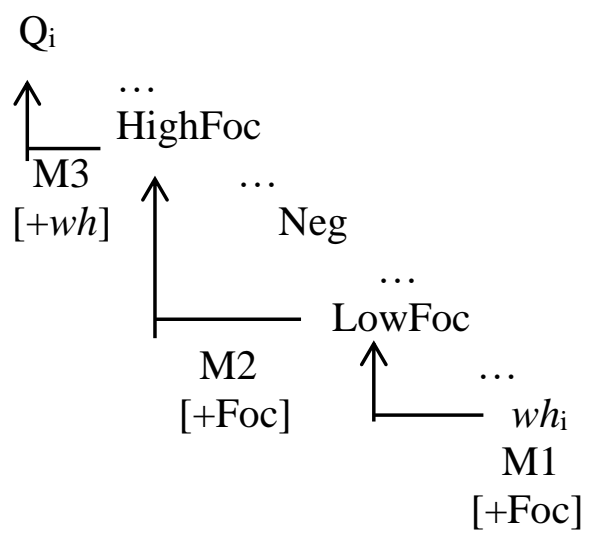

M1: overt phrasal movement; M2: overt phrasal movement; M3: feature movement

Wh-arguments that are base-generated below negation yet have undergone obligatory movement in LAC undergo feature movement, thus being sensitive to the Intervention Effect. As discussed previously, Q-binding of $w h$-nominals cannot cross negation-induced barriers, so $w$ h-arguments move to a position c-commanding the interveners, as in the second sentence of (28).

\begin{tabular}{|c|c|c|c|c|c|c|c|c|}
\hline $\begin{array}{l}\text { (28) 然则 } \\
\text { 子・秋水) }\end{array}$ & 我 & 何 & 爲 & 乎? & 何 & 不 & 爲 & 乎? \\
\hline $\begin{array}{l}\text { Ránzé } \\
\text { then }\end{array}$ & $\begin{array}{l}\text { wǒ } \\
\text { I }\end{array}$ & $\begin{array}{l}\text { hé }_{i} \\
\text { what }\end{array}$ & $\begin{array}{c}\text { [vP wéi } \mathrm{t}_{\mathrm{i}} \text { ] } \\
\text { do }\end{array}$ & $\begin{array}{l}\text { hū? } \\
\mathrm{Q}\end{array}$ & $\begin{array}{l}\text { Hé }_{j} \\
\text { what }\end{array}$ & bù & $\begin{array}{c}\text { [vP wéi } \mathrm{t}_{\mathrm{j}} \text { ] } \\
\text { do }\end{array}$ & $\begin{array}{l}\text { hū? } \\
\mathrm{Q}\end{array}$ \\
\hline
\end{tabular}


'Then what do I do? What (do I) not do?'

The first sentence in (28) demonstrates that the wh-DP can move overtly (and actually, it has to, because of obligatory wh-fronting), which is a precondition for its movement past negation in the second sentence.

This is also the case for preposed $w h$-adverbials below negation. The $w h$-adverbial in (29a) has undergone overt movement, and the diagnostic element $d u$ indicates that the landing site is the Low focus position. However, if the Q-binding is blocked by a c-commanding negator, the wh-adverbial has to raise to a higher landing site above negation, i.e. the High focus position, as in (29b). That is to say, adverbial wh-phrases are also subject to the blocking effect, analogous to $w h$-arguments.

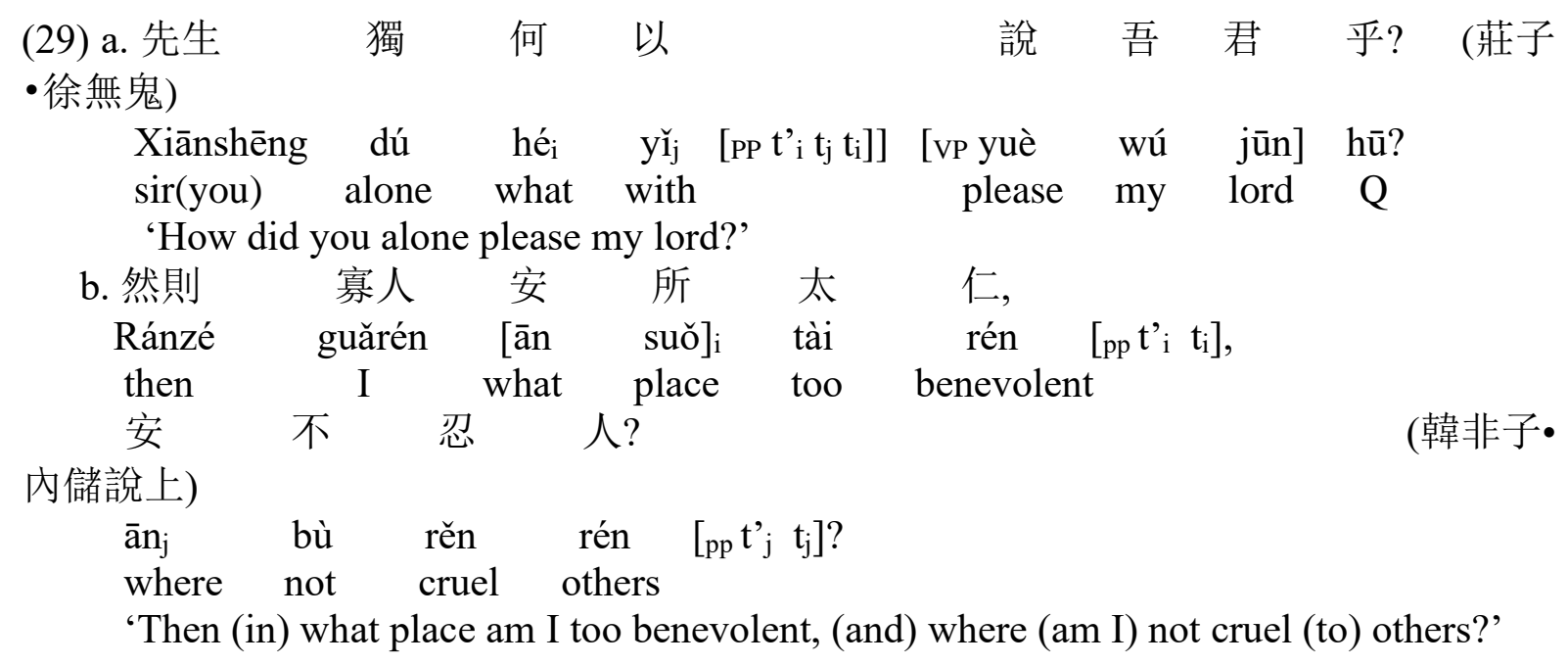

In LAC, obligatory $w h$-in-situ is strong enough to circumvent the blocking effect of negation, allowing a $w h$-variable to be bound even remaining in situ. When $w h$-DPs function as the second complement of ditransitive verbs nài/ruò/rú, they are not permitted to move. These in situ $w h$-items can undergo covert phrasal movement and hence are not affected by the Intervention Effect. Even if negation is present, these wh-DPs can (and have to) stay in situ and do not move across negation (30). That is to say, the ban of feature movement determines that the configuration $* w h$-Neg-V-DP (derived from Neg-V-DP- $w h$ ) is never attested.

(30) 孤 無 奈 越之先君何 (國語・吳語; Aldridge 2010: 25)

Gū wú nài [yuè zhī xiān jūn] hé I not.have treat Yue Gen former lord what

'There was nothing I could do about the former lord of Yue'

The third condition for the Intervention Effect is that the landing sites of overt whmovement are subject to locality restriction. Non-topical wh-movement in LAC is clauseinternal (Aldridge 2006, 2007, 2010), so a focal wh-element can never be preposed to a position above TP via an application of the repair strategy. As a consequence, focus and quantificational expressions fail to trigger the Intervention Effect, because if focalised whitems were to move across them, these $w h$-items would end up in the left periphery, violating the locality restriction.

Focus expressions in LAC do not display the blocking effect. The lack of the Intervention Effect caused by focus coincides with the prediction made by the locality restriction that a 
wh-phrase with [+Focus] feature cannot front to a position preceding a focalised subject.

In (31), the focused constituent is a subject, so in order to circumvent the blocking effect, the $w h$ has to raise from its base position to a position preceding the focalised subject, viz. some position in the clause-external left periphery, which is predicted to be infeasible. Such a prediction is indeed borne out: the configuration of $* w h_{\mathrm{Foc}}[\mathrm{TP} \ldots]$ is never attested in LAC. That is to say, in order not to challenge the locality restriction, the focus construction in Focwh needs to permit the $w h$-variable to be bound even remaining in a c-commanded position (31).

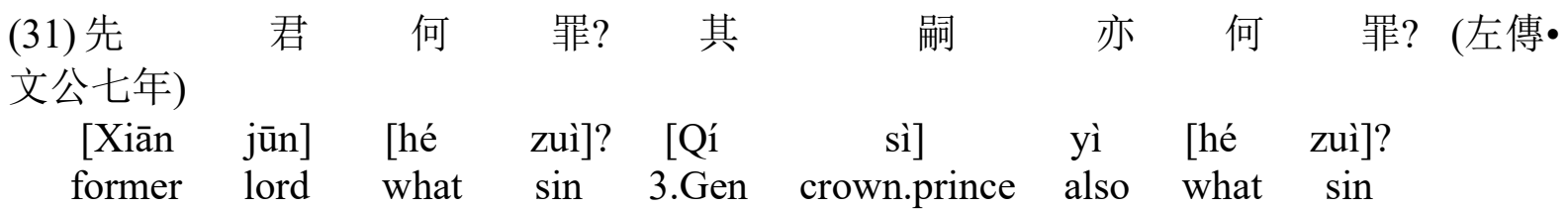

'What sin did the former lord (have)? What sin does his crown prince, too, (have)?'

This proposal of locality restriction also coincides with the lack of any blocking effect from quantificational elements in LAC. The proposal of locality restriction predicts that a whphrase cannot front across a quantified subject, and this prediction is indeed borne out.

In (32), the quantifier 皆 jie 'all' c-commands a $w$-variable 何 hé 'what' that raises to a focused position triggered by obligatory $w h$-fronting. If this quantifier were a barrier and the repair strategy needed to be employed, hé would front to a position structurally even more prominent than the quantified element. Parallel to its counterpart $d \bar{o} u$ in modern Mandarin, the quantifier jie in LAC only quantifies an NP to its left (Aldridge 2013). Therefore, the quantifier $j i \bar{e}$ in (32) is supposed to be subject-oriented, immediately following and quantifying over the (empty) subject. To circumvent the Intervention Effect, hé has to front to a position above the quantified (null) subject and jiē, but neither the High nor the Low focus position is high enough, so that means hé has to target some position above TP. Given the restriction of mere clause-internal movement on non-topical wh-constituents, this focused $w h$-word hé cannot front to the left periphery, so no further $w h$-fronting has happened. As a consequence, this quantificational expression fails to induce any intervening effect.
(32) 皆
何
以
稱
人?
(公羊傳・桓
公十五年)

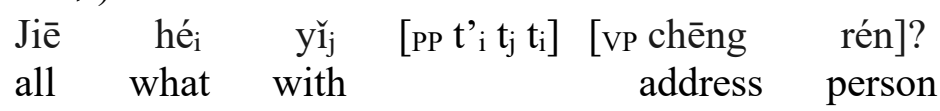
'With what do (we) all address those people?'

\section{Conclusion}

In this article, I analyse the inverted structure of $w h-\mathrm{P}$ in LAC and illustrate that such a reverse order is generated via PP inversion followed by separate movement of $w h$ and P. There are three steps in total. First, $w h$ raises to a specifier position within PP. Second, $w h$ further moves to the specifier position of a functional projection. Third, the head preposition moves to the head position of the corresponding functional projection. If the wh-PP is basegenerated postverbally and moves to a preverbal position, the preposition has to first incorporate to $\mathrm{a} \mathrm{V}^{0}$ and then move to the head of the functional projection through excorporation.

I also investigate the Intervention Effect which is triggered by negation. Both $w h$-arguments and $w$ h-adjuncts fronted to the Low focus position below negation are subject to the blocking effect induced by negators. In a negative context, these wh-phrases have to land in the High 
focus position above negation which is expected to accommodate 'high' reason adverbials exclusively. The Intervention Effect requires that interrogative $w h$-items are permitted to undergo feature movement, and their fronting must not violate the locality restriction.

\section{References}

Aldridge, E. 2006. "VP-internal quantification in Old Chinese". Chinese Linguistics in Budapest: 1-15.

Aldridge, E. 2007. "Wh-indefinites and their relation to wh-in-situ". Proceedings of the 43rd Meeting of the Chicago Linguistics Society: 139-153.

Aldridge, E. 2010. "Clause-internal wh-movement in Archaic Chinese". Journal of East Asian Linguistics 19: 1-36.

Aldridge, E. 2012. PPs and Applicatives in Late Archaic Chinese. Studies in Chinese Linguistics 33: 139-164.

Aldridge, E. 2013. "Object relative clauses in Archaic Chinese". Canadian Journal of Linguistics 58.2: 239-265.

Aldridge, E. 2015. Pronominal Object Shift in Archaic Chinese. In Syntax over Time: Lexical, morphological and information-structural interactions, eds. Theresa Biberauer and George Walkden, 350-370. Oxford University Press.

Beck, S. 1996. "Quantified structures as barriers for LF movement". Natural Language Semantics 4: 1-56.

Beck, S., \& S.-S. Kim. 1997. “On wh- and Operator Scope in Korean”. Jornal of East Asian Linguistics 6: 339-384.

Chomsky, N. 1981. Lectures on Government and Binding. Dordrecht: Foris.

Chomsky, N. 1982. Some concepts and consequences of the theory of Government and Binding. Chicago: MIT Press.

Chomsky, N. 1986. Barriers. Linguistic Inquiry Monograph 13. Cambridge: MIT Press.

Djamouri, R. 2001. "Markers of predication in Shang bone inscriptions". In Synchronic and Diachronic Perspectives of the Grammar of Sinitic Languages, ed. H. Chappell, 143171. Oxford: Oxford University Press.

Djamouri, R., W. Paul, \& J. Whitman. 2012. "Syntactic change in Chinese and the argumentadjunct asymmetry". In Breaking Down the Barriers: Interdisciplinary Studies in Chinese Linguistics and Beyond, edited by G. Cao, H. Chappell, R. Djamori and T. Wiebusch, 577-594. Taipei: Academia Sinica.

Dong, H. 2014. A History of the Chinese Language. London: Routledge.Feng, S. 1996. "Prosodically constrained syntactic changes in Early Archaic Chinese". Journal of East Asian Linguistics 5: 323-371.

Huang, C.-T. J. 1982. "Logical relations in Chinese and the theory of grammar". PhD diss., MIT.

Huang, C.-T. J. Y.-H. A. Li and Y. Li. 2009. The Syntax of Chinese. New York: Cambridge University Press.

Karlgren, B. 1923. "Analytic Dictionary of Chinese and Sino-Japanese”. Paris: Geuthner.

Kim, S.-S. 2002a. "Intervention effects are focus effects". In Japanese/Korean Linguistics 10, ed. N. Akatsuka and S. Strauss, 615-628. Stanford: Center for the Study of Language and Information.

Kim, S.-S. 2002b. "Focus Matters: Two Types of Intervention Effect". Paper presented at WCCFL 21, Santa Cruz.

Kim, S.-S. 2006. "Intervention effects in questions". Ph.D. dissertation, University of Frankfurt.

Meisterernst, B. 2008. "Modal verbs in Han period Chinese Part I: The syntax and semantics of kĕ 可 and kě yı̆ 可以”. Cahiers de Linguistique-Asie Orientale 37.1: 85-120. 
Meisterernst, B. 2010. "Object Preposing in Classical and pre-Medieval Chinese". Journal of East Asian Linguistics 19: 75-102.

Norman, J. 1988. Chinese. Cambridge: Cambridge University Press.

Paul, W. 2002. "Sentence-internal topics in Mandarin Chinese: the case of object preposing". Language and Linguistics 3.4: 695-714. Taipei: Academia Sinica.

Paul, W. 2005. "Low IP area and left periphery in Mandarin Chinese". Recherches linguistiques de Vincennes 33: 111-134.

Peyraube, A. 1996. "Recent Issues in Chinese Historical Syntax". In New Horizons in Chinese Linguistics, ed. C.-T. J. Huang and Y-H. A. Li, 161-214. Dordrecht: Kluwer.

Peyraube, A. 1997. "On word order in Archaic Chinese". Cahiers de linguistique Asie Orientale, 26 (1): 3-20.

Peyraube, A. 2002. "On moving constituents in Chinese historical syntax". D. Ho (ed.). Historical Development of Chinese Language, Taipei: Academia Sinica - Institution of Linguistics. 141-156.

Peyraube, A. 2008. Ancient Chinese. The Ancient Languages of Asia and the Americas: 136162.

Peyraube, A. and F. Wu. 2005. Origin and evolution of question-words in Archaic Chinese: A cognitive approach. Cahiers de linguistique-Asie Orientale 34.1: 3-24.

Pulleyblank, E. G. 1995. Outline of Classical Chinese Grammar. Vancouver: University of British Columbia Press.

Roberts, I. 1991. "Excorporation and minimality". Linguistic Inquiry 22: 209-218.

Roberts, I. 2001. "Head movement". In The Handbook of Contemporary Syntactic Theory, edited by Mark Baltin and Chris Collins, 113-147. Oxford: Blackwell Publishing.

Rooth, M. 1996. "Focus". In The handbook of contemporary semantic theory, ed. S. Lappin, 271-297. Oxford: Blackwell.

Shaughnessy, E. L. 1985. Zhouyuan Oracle-Bone Inscriptions: Entering the Research Stage? Early China 11/12: 146-163.

Soh, H. L. 2005. "Wh-in-situ in Mandarin Chinese”. Linguistic Inquiry 36.1: 143155.

Stepanov, A. 2001. "Late adjunction and minimalist phrase structure". Syntax 4, 94-125.

Stepanov, A. 2007. "The end of CED? Minimalism and extraction domains". Syntax 10:1, 80126.

Travis, L. D. 1984. "Parameters and effects of word order variation". PhD diss., MIT.

Wang, A. 2013. "Object preposing in Late Archaic Chinese". York Papers in Linguistics 13: $70-98$.

Wang, A. 2015. "The Intervention Effect of negation on wh-adverbials in Late Archaic Chinese". Proceedings of the Second Asian and European Linguistic Conference (AELink 2): 160-172.

Wang, A. 2016. "Clause-internal preposing in Late Archaic Chinese". PhD diss., University of York.

Wang, L. 1958. "Hanyu shigao [History of Chinese]". Reprinted in 2004. Beijing: Zhonghua Shuju.

Wilkinson, E. 2000. Chinese History: A Manual. Cambridge, MA: Harvard University Asia Center.

Xu, D. 2006. Typological Change in Chinese Syntax. Oxford: Oxford University Press.

Xu, J. \& Y. Li. 1993. "Jiaodian he liangge fei xianxing yufa fanchou: fouding yiwen [Focus and two nonlinear syntactic scopes: negation, interrogation]". Zhongguo Yuwen 2: 8192.

Zhou, F. 1963. "Stages in the development of the Chinese Language". In Zhongguo yuwen luncong, edited by F. Zhou, 432-438. Taipei: Zhengzhong Shuju. 


\section{AUTHOR'S BIO}

Aiqing Wang, Ph.D. is currently employed by Lancaster University as a Senior Teaching Associate in Chinese Studies. After graduating with a Master of Arts in Linguistics from University College London, she received a PhD in Linguistics from the University of York, and her doctoral project investigated Late Archaic Chinese syntax. Apart from syntax, her ongoing research interests also include cultural studies. 